\title{
RESULT VERBS, SCALAR CHANGE, AND THE TYPOLOGY OF MOTION VERBS
}

\begin{abstract}
JOHN BEAVERS
ANDREW KoONTZ-GARBODEN

The University of Texas at Austin

The University of Manchester

In this article we consider the nature of 'result verbs', typically defined as verbs describing scalar changes, which have played a significant role in the literature on verb typologies, event structures, and theories of (im)possible word meanings. We argue that the entailment of scalar change and the entailment of a new result state should not be wholly conflated. Rather, various previously proposed diagnostics for scalar change actually pick out at least two distinct notionsentailing change along a scale regardless of whether a new state obtains for the theme argument, more broadly, and change along a scale that does result in a new state, more narrowly. We specifically examine verbs of manner of motion, with a special emphasis on the verb climb, and show that there is a subclass of manner-of-motion verbs that entail scalar change without a new result and are themselves also cross-classified by other standard distinctions among scalar change verbs. These observations have several consequences. First, manner-of-motion verbs are not as distinct from path verbs as prior work in the Talmy typology has suggested. Second, prior diagnostics for identifying result verbs and subtypes of result verbs are sensitive to the various distinctions we propose, producing more nuanced results than previously assumed. Third, the observation that a large swath of manner-of-motion verbs also have result entailments further supports the conclusion in Beavers \& Koontz-Garboden 2012 that there is no truth-conditional manner/result complementarity in verb meaning, expanding the base of potential counterexamples and raising questions about how the claim is meant to be interpreted.*
\end{abstract}

Keywords: lexical semantics, verb classes, change of state, manner, motion typology

1. IntRoduction: 'RESUlt' in LexicAl SEMANTICS. The set of attested verb meanings in any language is a small subset of the meanings that could conceivably be lexicalized by verbs. Whether this set is constrained, at least in part, by the nature of grammar is a long-standing question in the study of syntax and semantics, going back at least to the days of GENERATIVE SEMANTICS. Following in this tradition, a considerable body of recent work aims to pin at least some of the restriction on possible verb meanings on the nature of a verb's 'event structure', a level of representation associated (lexically or syntactically) with a surface verb that is meant to figure into generalizations about its argument-realizational and lexical-aspectual properties, among other things (see e.g. Dowty 1979, Pinker 1989, Jackendoff 1990, Levin \& Rappaport Hovav 1995, Van Valin \& LaPolla 1997, Wunderlich 1997, Davis \& Koenig 2000, Davis 2001, inter alia; see also Lakoff 1965, McCawley 1971, Ross 1972, Hale \& Keyser 1993, 1997, 2002, Pesetsky 1995, Baker 1997, Marantz 1997, Folli \& Ramchand 2002, Harley 2003, Folli \& Harley 2004, Ramchand 2008, inter alia on theories that take event structures to be phrase-structural objects). On such theories an event structure consists of two main components: (i) an 'event template' that defines the broad aspectual and causal structure of the event, built recursively from a small set of basic universal eventdenoting primitives (e.g. CAUSE, BECOME, ACT), and (ii) some idiosyncratic 'root' that fills in the real-world details of the event template associated with a given verb. The

* We would first and foremost like to thank Chris Kennedy and three anonymous Language referees for their extensive and detailed feedback on this article. We also thank Beth Levin and Malka Rappaport Hovav for their very helpful feedback, as well as the audience at the Roots IV Workshop held at NYU in 2015 and the members of the Spring 2015 seminar on lexical semantics at The University of Texas at Austin. Thanks also are due to Michael Everdell, Kyle Jerro, Elise LeBovidge, Jacques Lefleur, Stephen Nichols, Melinda Nobles, Danny Tobey, and Judith Tobey for further commentary and judgments on particular examples. This material is based upon work supported by the National Science Foundation under grant no. BCS-1451765. 
intuition behind work in this area is that certain conceivable verb meanings are precluded by combinatoric rules for deriving possible event structures, thus ruling out particular argument structures and aspectual properties with verbs that have particular meanings. It furthermore predicts that particular kinds of verb meaning should not occur at all, thus deriving typologies of possible verb meanings and a constrained theory of verb classes. ${ }^{1}$

One very broad verb-class distinction within this tradition which has figured significantly in the literature on verb meaning is the distinction between manner and result verbs (Rappaport Hovav \& Levin 1998), that is, verbs built around a core ACT primitive that describe actions but not the outcomes of those actions (e.g. jog, swim, rub, caress, sneeze, play) vs. verbs built around a core BECOME primitive that describe events with specific outcomes but not what actions lead to those outcomes (e.g. break, crack, cool, cover, transform), where the relevant outcomes are now typically analyzed as having truth conditions of 'scalar change' in some event participant along a scale of possible changes defined by the verbal predicate (Rappaport Hovav 2008, Beavers \& Koontz-Garboden 2012). The manner/result distinction is claimed to figure into a verb's aspectual properties (e.g. manner verbs tend to project activities, and result verbs accomplishments or achievements, roughly), argument-structural properties (e.g. dyadic result verbs tend to be more canonically transitive than dyadic manner verbs), and lexical entailment patterns (e.g. manner and result verbs entail different kinds of things about what happens in the event described). Relatedly, as discussed in Beavers 2011b, 2013, result verbs also fall into various subcategories, underpinned by the different kinds of scales of change a verb may lexicalize (e.g. change in position, change in quantity, change in some qualitative property of the theme argument), and also by how specific the verb is about the result that obtains (e.g. whether the verb lexicalizes a specific result state on the scale for its theme or just that some new state on the scale obtains, known as the quantized vs. nonquantized change distinction of Hay et al. 1999), all of which are also significant for determining a verb's aspectual properties. These correlating properties thus serve as diagnostics for whether a verb is a manner or result verb. The distinction between manner and result verbs has furthermore been argued to crosscut a range of broader semantic domains (Levin 2015; see table 3 in particular), such as verbs of putting (e.g. manner smear, pour vs. result cover, fill), removal (e.g. manner scrub vs. result clean), killing (e.g. manner stab vs. result kill), and especially motion, seeming to underlie the well-known distinction between manner-of-motion verbs (jog, run) and path verbs (enter, cross) that is at the heart of the influential motion typology of Talmy $(1975,1985,2000)$. Finally, the manner/result distinction has figured into recent work on so-called manner/result complementarity, the hypothesis that a given monomorphemic verb will lexically entail either a manner or a result but not both (Goldberg 2010, Rappaport Hovav \& Levin 2010, Husband 2011, Beavers \& Koontz-Garboden 2012, Mateu \& Acedo-Matellán 2012, Levin \& Rappaport Hovav 2013, Rissman 2016), thus delimiting the range of possible verb meanings available in a language.

In this article we offer a critical reexamination of the definition of 'result' and its equation to scalar change within theories of verb classes and possible verb meanings, and suggest that this equation actually conflates two interrelated but distinct notions. In particular, the intuitive definition of a result is that some event participant is in a new state (on a scale) at the end of the event that did not hold of it at the beginning of the

\footnotetext{
${ }^{1}$ The key semantic ingredients relevant for grammar assumed in event-structural theories may in turn be determined by the cognitive tasks associated with grammar, such as acquisition; see Koenig et al. 2015.
} 
event (Koontz-Garboden 2010, Beavers 2011b). Yet as we demonstrate, nearly all previously proposed diagnostics for result verbs pick out predicates that describe change along a scale over the course of the event regardless of whether this leads to a new final state, meaning that the entailment of change along a scale need not involve a new final state. We thus propose that 'result verb' is a more diverse category than previously acknowledged, including both 'scalar change verbs', which describe events in which a participant undergoes transitions along a scale regardless of whether a new state obtains, and a strict subset of those we call 'scalar result verbs' that entail a new final state at the end of the event, a distinction independent of and crosscutting other parameters of scalar change verbs mentioned above.

Our point of departure is the truth-conditional content of one particular verb, climb, whose lexical entailments have been the subject of much discussion in prior work (see Fillmore 1982, Jackendoff 1985, Geuder \& Weisgerber 2008, inter alia). Most recently, Levin and Rappaport Hovav (2013:58-66) argue that climb actually has two distinct uses, one a manner verb and one a result verb. However, we argue that all uses of climb in fact entail scalar change qua change along a path or positional scale, despite not entailing a new position of the theme, and that this correlates with climb otherwise passing other standard result-verb diagnostics. This is distinct from canonical result verbs, which entail scalar change and also a new result, justifying the distinction between scalar change more broadly and scalar result more narrowly. We further show that there is one use of climb, nonderivable from all others, that entails that its theme move a specific distance along its path, deriving that scalar result necessarily follows in many (but not all) contexts. The possibility of scalar change without scalar result with climb we ultimately argue derives from special properties of motion scales. In particular, motion scales allow measured changes that crucially may loop back onto themselves in ways other scales do not. Different apparent senses of climb arise from how these properties of motion scales intersect with previously proposed subtypes of scalar change, in particular nonquantized vs. quantized change.

These results have relatively far-reaching consequences. First and foremost, climb is not an isolated example. We argue that climb also entails manner, understood in this context as a type of resistance to gravity (following Levin \& Rappaport Hovav 2013:59-61 and Geuder \& Weisgerber 2008, slides 97-171). This opens up the possibility that other manner-of-motion verbs may entail scalar change despite not entailing a canonical result, and we show that this is indeed the case. This shows that the common distinction of manner vs. path verbs in work on Talmyan motion typology is not as clearly dichotomous as typically assumed, and that manner-of-motion verbs as a class are not the canonical manner verbs they seemed to be (contra Rappaport Hovav \& Levin 2010:27), with potential consequences for theories based on these assumptions. Second, our proposal raises the question of how previously proposed result diagnostics - which were largely designed to pick out a simple dichotomy between manner and result verbs - are to be interpreted in light of more diverse subtypes of scalar change verbs. In particular, we review and expand the result tests in Beavers \& Koontz-Garboden 2012:336-42, showing that in some cases what a given test picks out is the broader notion of scalar change, and in others the more narrow notion of scalar result. Furthermore, tests for other subtypes of scalar change from the formal semantic literature must also be revisited on similar grounds. We additionally note that some result tests are actually sensitive to scale dimension plus the additional presence of manner in a verb's meaning (plus other grammatical properties), further complicating the conclusions one can draw from them. Third, our conclusions resolve the debate about whether climb is a 
manner verb, a result verb, or ambiguous, since we ultimately argue it has both kinds of entailments. It and other manner-of-motion verbs we discuss thus counterexemplify manner/result complementarity as a truth-conditional claim about possible verb meanings, further adding to the conclusion of Beavers \& Koontz-Garboden 2012 that this hypothesis does not hold as a claim about the lexical entailments of particular verbs (even if it may hold as a constraint on possible event structures, as suggested in Beavers \& Koontz-Garboden 2012 and Mateu \& Acedo-Matellán 2012).

In $\$ 2$ we discuss climb and the claim that it does not entail a result, demonstrating that it does in fact entail scalar change. We also show that scalar change verbs do not all fit comfortably with the intuitive notion of result, additionally discussing some of the subtypes of such verbs and the consequences of their existence for result/scalar change diagnostics. We then demonstrate that climb also entails manner ( $\$ 3)$, and we extend our analysis to the broader class of manner-of-motion verbs and show that a subset, including slide, ski, and roll (among others), also have entailments of scalar change, calling into question the traditional manner vs. path verb distinction. We discuss additional complications these verb classes have for interpreting result diagnostics in $\S 4$, and in $\S 5$ we discuss the ramifications our observations have for manner/result complementarity, before concluding $(\S 6)$.

Before we continue, we offer one methodological clarification. Our main goal is to understand the truth conditions of result as a lexical semantic primitive in theories of verb meaning. Technically, though, result entailments arise not only with simple, monomorphemic verb meanings, but also in the context of larger constructions, for example, verb-plus-PP combinations. However, since we are interested here in verb classes and limits on possible verb meanings, such as the manner/result complementarity hypothesis and the path vs. manner verb distinction in the domain of motion verbs, we focus on the entailments of monomorphemic surface verbs independent of the constructions they occur in (though we sometimes reference result within larger verbal predicates for illustrative purposes). Our assumption (following Rappaport Hovav \& Levin 2010:1, inter alia) is that entailments that survive across the grammatical contexts a surface verb occurs in come from the surface verb itself, though we allow that surface verbs may also be polysemous if it can be shown that they have multiple uses that are not reducible to a single sense. A further question, though, is how to understand the surface verb's semantic contribution in light of specific theories of event structures, and in particular whether particular entailments come from the root or the template associated with the surface verb (building on Grimshaw 2005:75-88). The answer may vary somewhat depending on the specific framework of event structures adopted. For example, if event structures are lexical representations associated with a surface verb that are related to the syntax via realization or correspondence rules, then a surface verb's meaning in principle could be a consequence of its lexical-semantic root or the lexical-semantic event template. Alternatively, if event structures are viewed as phrase-structural objects, then surface verb meaning often reduces to root meaning since the standard assumption is that the surrounding construction the verb occurs in is the template. ${ }^{2}$ To answer this question, however, would require detailed work exploring the particular templatic structures of the verbs we discuss, plus formalizing the analysis in a particular eventtemplatic framework. This would take us too far afield from our larger central goal, and thus we leave it for future work.

\footnotetext{
${ }^{2}$ Technically, though, this assumption need not hold necessarily, if it can be shown that all instances of a surface verb involve at least some of the same templatic structure.
} 
2. The Result entailments of climb. Rappaport Hovav and Levin (2010:28) define 'result' as scalar change - that is, a result verb describes events in which a participant undergoes a change along a scale - and Beavers and Koontz-Garboden (2012: 336-42) elaborate several properties that identify when a verb entails it. We appeal to these tests - plus others we introduce below-to demonstrate that climb entails scalar change, contra some earlier work. However, we also suggest there is lack of clarity on what constitutes scalar change vis-à-vis these diagnostics, and once this is clarified the notion of result verb actually encompasses two distinct but related notions: a broader class of verbs that describe changes along a scale and a narrower subclass that additionally entail a new final state on this scale, both being linguistically significant in that each is picked out by previously proposed result tests qua constructions they occur in and the broad types of inference patterns they generate. We also show that this distinction crosscuts other distinctions among scalar change verbs, in particular the nonquantized/quantized change distinction, which produces a more diverse typology of scalar change verbs and their linguistic properties than previously acknowledged. First, though, we consider whether climb entails upwardness, something that has figured into discussions of whether it is a result verb, but which we argue is tangential. This discussion is nonetheless important because it establishes that there are distinct uses of climb, relevant for our discussion of whether it entails scalar change and, if so, what kind.

2.1. UPWARDNESS IN climb. The debate about result in climb's meaning has centered around whether it entails upward trajectory (Levin \& Rappaport Hovav 2013:58, 62-66), with data like 1 putatively showing it does not.

(1) Bill climbed down the ladder.

(Jackendoff 1985:275, ex. 8)

Levin and Rappaport Hovav (2013:62-66) take data like 1 as a point of departure for their claim that climb does not entail result. Rather, following Kiparsky (1997:490), they claim that the verb only entails upwardness (qua result) if it does not simultaneously entail manner, consistent with manner/result complementarity (see also Jackendoff 1985:286-91 and Fillmore 1982:32).

It is certainly true that some uses of climb do not entail that the theme moves up. In addition to grammatically intransitive uses of climb (i.e. lacking a direct object, but with an optional PP or particle specifying direction or goal as in 1), there are transitive uses of climb that also do not entail upwardness as in 2, in which climb occurs with a directional particle and goal $\mathrm{PP}$.

(2) You climb the ladder down into the crew quarters, and encounter a Protagonist, lying on a cot and brooding.

(Levin \& Rappaport Hovav 2013:64)

Taken together, 1 and 2 suggest that, in principle, any direction is possible with climb.

However, there is one use of climb, distinct from all others, that does require upwardness: transitive climb occurring with a direct object DP but absent directional particles/PPs, as in 3.

(3) Kim climbed the stairs.

The object DP in 3 looks superficially like a 'traversal' object describing the entirety of the path traversed by the theme (see e.g. Mateu \& Acedo-Matellán 2012:220-22), as found optionally with many otherwise intransitive manner-of-motion verbs (Levin 1993: 43-44, Krifka 1998:224-25, Beavers 2010:851-53, inter alia).

(4) a. John hiked (the Appalachian Trail).

b. John swam (the English Channel).

Consistent with the traversal objects in 4 , climb in 3 requires (relatively) complete traversal of the path, so that the sentences are unacceptable if only a small part of the path is traversed. 
(5) a. \#Kim climbed the stairs, but only made it two steps before giving up.

b. \#John hiked the Appalachian Trail, but only took two steps before giving up.

c. \#John swam the English Channel, but only made it ten feet before turning back.

Crucially, however, simple transitive climb in 3 has one additional entailment lacking for the other verbs in 4 with overt path objects, namely, that the direction must be upward.

(6) \#Kim entered the house on the ground floor and immediately climbed the stairs, quickly reaching the basement.

In 4 any direction compatible with the path is acceptable, such as up or down, as in 7 , or from any end to any other, as in 8 (and thus that there is no 'up' in the metaphorical sense of going north).

(7) a. John hiked the Appalachian Trail, ending up higher/lower than when he started.

b. John swam the English Channel, ending up higher/lower than when he started.

(8) a. John hiked the Appalachian Trail from Maine to Georgia/from Georgia to Maine.

b. John swam the English Channel from England to France/from France to England.

Thus simple transitive climb as in 3 has a unique property not found with other verbs with traversal objects, namely a specific directionality. It therefore cannot be analyzed as the output of applying some traversal-object addition rule independently attested in 4 to an intransitive use of climb. Furthermore, simple transitive climb is not simply transitive climb with a PP or particle, as in 2, but with the PP or particle dropped or unrealized, since again simple transitive climb has an entailment of upwardness that the variants with a PP or particle do not have, as in 1 and 2. Putting these facts together, transitive $\operatorname{climb}$ with a DP object and no directional PP or particle dependents must be analyzed as somehow distinct from other uses of climb, meaning that at least one use of climb does require upwardness.

Levin and Rappaport Hovav (2013:63-64) argue that upwardness with strictly transitive climb is not an entailment, but rather 'follows from properties of the direct objectthe reference object - and in particular, the way in which agents typically interact with this object'. Thus climb the tree entails upwardness because trees 'are perceived as projecting upward from the ground, so they are typically encountered as something to ascend, especially because they might contain fruits or provide a haven from danger'. If this were true, it should be possible to find strictly transitive climb on a downward reading with just the right path object. Stairs descending to a basement in 6 is such an example, since they project downward from the canonical position from which they are viewed. However, the first clause in 6 is unacceptable in a downward context, suggesting that simple transitive climb actually ENTAILS upwardness, further illustrated in 9 (see also Geuder 2009, passages 9-11, 18, for related discussion of French and Spanish 'climb' verbs).

(9) a. \#John leapt from the top of one tree to the top of [the next $]_{i}$, then immediately climbed it $_{i}$.

b. \#Once he realized the building was on fire, John scrambled to [the fourth floor fire escape ladder $]_{i}$ and quickly climbed $i_{i}$, reaching the ground in less than a minute.

c. \#After his stint as the ship's lookout ended, John exited the lookout perch, climbed the mast, and returned to his cabin below. 
As a referee reminds us, the behavior of climb contrasts with a verb like scale, which also has an association with upwardness in its transitive use (e.g. John scaled the wall by default conveys upward scaling) but where in a specific context this may not obtain, as in the following naturally attested example from Levin \& Rappaport Hovav 2008:13.

(10) A woman escaped with minor injuries after her car plunged over cliffs in East Sussex and landed on a ledge ... A coastguard team scaled the cliff to reach the woman who was then winched to safety and taken to a hospital. ${ }^{3}$

Thus upwardness with simple transitive climb is not a pragmatic effect-it is a lexical entailment arising with this specific usage, motivating it as distinct from all the others. ${ }^{4}$

In sum, there are three distinct uses of climb: (i) intransitive $c \lim b_{\text {itr }}$ (which may additionally occur with a particle or PP indicating direction and/or goal), (ii) transitive $c l i m b_{\text {tr }+\mathrm{PP}}$ accompanied by a directional particle or PP, and (iii) transitive $c$ limb $b_{\mathrm{tr}}$ with just a direct object and no directional XP. The former two are unspecified for directionality, while the last entails upward motion. There is an open question of how to analyze these uses. The simplest analysis would be to say that each is a distinct sense of climb with distinct lexical entailments and a distinct argument structure that determines the grammatical context it occurs in (e.g. Mateu and Acedo-Matellán (2012:217-23) assign three separate event structures with a single shared root to $\operatorname{climb}$ ). Alternatively, $c \lim b_{\text {itr }}$ and $c$ limb $b_{\text {tr }+ \text { PP }}$ might just reflect a single intransitive sense taking an optional PP or particle, with $c$ limb $b_{\text {tr }+\mathrm{PP}}$ derived by a general operation of traversal-object addition, as available for other manner-of-motion verbs that do not otherwise take (obligatory) objects as in 4, with climb $_{\text {tr }}$ as a distinct, separate transitive sense. Finally, a referee suggests another alternative whereby climb has a single sense that lexically entails upwardness, but that when placed into syntactic contexts with a PP or particle, upwardness is dropped in favor of the directionality of the PP or particle (something that would be very much in the spirit of Jackendoff 1985:286-91, but which we are unsure how to implement compositionally). ${ }^{5}$ In all of these possible analyses of the different uses of climb, however, there is always at least one sense of climb that entails upwardness, and that was the key point we intended to motivate here. For simplicity of exposition, we set the issue aside and assume the three-way polysemy analysis going forward.

2.2. The nature of SCAlar Change entailments. Having established a distinct sense of climb that entails upwardness, we now argue that upwardness is tangential to whether climb is a result verb. As laid out in Rappaport Hovav \& Levin 2010:28 and Beavers \& Koontz-Garboden 2012:336, a verb entails result if it lexically entails that one of its arguments undergoes a scalar change. We take a scale to be 'a set of degreespoints or intervals indicating measurement values - on a particular dimension (e.g. height, temperature, cost), with an associated ordering relation' (Rappaport Hovav \& Levin 2010:28). Predicates that entail change of location can be analyzed as entailing a scalar change, where the scale is a spatial scale, for example, a set of distances or points in space connected through adjacency relations and ordered by distance from the theme's initial position or other reference point over which change in the theme's position can

\footnotetext{
${ }^{3}$ http://news.bbc.co.uk/1/hi/england/southerncounties/3691952.stm, accessed October 1, 2017.

${ }^{4}$ Indeed, Levin and Rappaport Hovav's (2013:63-65) examples of transitive climb in nonupward contexts all involve a directional or goal XP, which we showed is a distinct use not entailing upwardness, and thus are irrelevant.

${ }^{5}$ The referee notes that, on this analysis, The sherpa climbed for hours but did not reach the summit before nightfall would be predicted to require upwardness. Our own judgments are that it does not. For example, we find this sentence acceptable in a context where the sherpa spent the day recreationally climbing and ends up at the same spot she started at.
} 
be calculated (Hay et al. 1999:139-40, Kratzer 2004:394-95, Beavers 2008:245-46, Kennedy \& Levin 2008:181-82, Rappaport Hovav 2008:17, 2014:267-73, Rappaport Hovav \& Levin 2010:29-32, inter alia; for specific such analyses of motion see Piñón 1993, Asher \& Sablayrolles 1996, Krifka 1998:222-31, Nam 2000, Zwarts \& Winter 2000, Zwarts 2005, 2006:8-18, 2008:80-97, Beavers 2011a:12-18, 2012a:29-52, inter alia). Furthermore, the relevant scale must be unique and isolatable from other aspects of the verb's meaning in order to contrast it with manner, which Rappaport Hovav and Levin (2010:12) analyze as 'nonscalar change', defined as 'any change that cannot be characterized in terms of an ordered set of values of a single attribute', usually due to being a confluence of many changes. In principle, however, those changes could include changes along scales, so to maintain a distinction between scalar and nonscalar change any scalar changes entailed by a given nonscalar change must be ignored. How to formalize this we set aside and leave to intuition (as in all previous work on this topic). ${ }^{6}$

So the issue of whether climb is a result verb must have to do with change along a scale, not upwardness. How can it be shown that climb has such a lexical entailment? In work on manner/result complementarity there have been three tests argued to diagnose result verbs (see Beavers \& Koontz-Garboden 2012:336-42). We begin with two of these here, and consider the third in the next section. The first is whether the verb obligatorily requires its theme to be expressed overtly. Typically, the theme is the object, so the prediction is that the object cannot be omitted through an otherwise attested operation of object drop, as illustrated in 11a for the canonical result verb break, vs. the canonical manner verb scrub as in $11 \mathrm{~b}$.

(11) a. All last night, Kim broke *(vases).

b. All last night, Kim scrubbed (floors).

Unfortunately, this test is inapplicable to climb, since the theme is the verb's subject, and English subjects must be overtly expressed for independent syntactic reasons. In $\S 3.2$, however, we consider other verbs taking theme objects in the broader class of manner-of-motion verbs that includes climb, and suggest that this test does indicate that verbs like climb entail scalar change.

The second diagnostic is whether the possible result XPs that can occur with the verb are limited. The logic is that result verbs already place constraints on the (possible) scalar result state(s) of their theme arguments, and if result XPs do the same (Wechsler 2005, Beavers 2008), then any scalar constraints imposed by the result XP must be compatible with those imposed by the verb, limiting the set of possible result XPs. Conversely, manner verbs impose no constraints on possible scalar results for any argu-

\footnotetext{
${ }^{6}$ One implementational question about a scalar analysis of motion verbs, much like the question of degrees as points vs. intervals in scalar analyses of adjectives (see e.g. Kennedy 2001, Schwarzschild \& Wilkinson 2002), is whether the scale should be interpreted as an ordering of positions on a path in some sense (i.e. the path is the scale; Krifka 1998:228-30, Zwarts 2006:18-20, 2008:98-103, Beavers 2012a:52-58) or as an ordering of distances from the source point (i.e. the scale is distance measured over the path; Hay et al. 1999:139-40, Tatevosov 2012). Given that motion predicates allow explicit measurements of distance and explicit XPs reflecting positions on the path (e.g. walk five miles vs. walk to the store), both of which figure into the predicate's aspectual properties (e.g. either can figure into telicity), both notions are needed somehow. A related issue (noted by a referee) is whether the fundamental notion is path or scale-in other words, whether scalar change should be reduced to (metaphorical) change along a path (as per Beavers 2012a), or change along a path should be reduced to (a type of) change along a scale (as per Hay et al. 1999). For our purposes, however, these implementational details do not matter, since either way there is measured change in space in the verb's meaning, the commonality across all approaches, and thus we set aside the question of how best to formalize motion vis-à-vis scalar change. Following in the tradition of work on result verbs, however, we continue to refer to the notion as 'scalar' change, albeit sometimes also using motion as a metaphor for the relevant change.
} 
ments, for lack of a scale, thereby allowing more result XPs. Thus canonical manner verbs, as in 12a, allow result XPs indicating results along a range of scales, as well as nonsubcategorized object resultatives, as in $12 \mathrm{~b}-\mathrm{c}$. Result verbs allow only result XPs that further specify the result along the scale already encoded by the verb, as in 13 .

(12) a. Cinderella scrubbed the table clean/shiny.

b. Cinderella scrubbed her knees sore.

c. Cinderella scrubbed her house-cleaning competitors out of business.

(13) a. Then the biologists dimmed the room to the level of starlight ... ${ }^{7}$

b. *We dimmed the room empty.

(Rappaport Hovav 2008:22-23)

c. *Kim dimmed her hand sore.

In $\S 4$ we reexamine this test and suggest that it is more nuanced than depicted here (or in prior literature). But the prediction for now is that if climb entails change along a path, it should allow goal PPs but not other result XPs. This is indeed the case. First, $c l i m b_{\text {tr }}$ does not technically take a goal PP since this sense is defined as taking no such PPs. But $c$ limb $b_{\text {tr }+ \text { PP }}$ is superficially what $c \lim b_{\text {tr }}$ would look like with a goal PP (minus obligatory upwardness), and here goal PPs are possible (taking goal PPs to be a type of result XP, as commonly assumed; see e.g. Beavers et al. 2010:358-60).

(14) a. In his black-framed glasses and narrow brimmed hat, Neville looked like a beatnik professor as he climbed the steps onto the stage. ${ }^{8}$

b. Soon we climbed the steep slope away from the river. ${ }^{9}$

Conversely, result XPs that specify other types of results are less acceptable with $c$ limb $b_{\text {tr }}$ or $\operatorname{climb}_{\text {tr }+\mathrm{PP} .}{ }^{10}$

(15) a. \#Being so weak from his recent illness that even the slightest physical exertion would take its toll on him, John climbed the ladder (to the top) to exhaustion/sleep.

b. \#Thanks to his severe vertigo, John climbed the ladder (to the top) unconscious/to unconsciousness.

c. \#John climbed the ladder (to the top) silly/sick, having gone up so high he got dizzy.

Still further, result XPs ascribing some resulting property of the path object are also odd.

(16) \#John climbed the ladder to pieces/thin/threadbare/shiny due to his heavy, rough-bottomed work boots.

Thus $c \operatorname{cim} b_{\text {tr }}$ admits no result XPs that do not further specify the outcome of the inherent scalar change of motion (or indeed any result XPs at all), and neither does $c l i m b_{\text {tr }+ \text { PP. }}$.

As for $c$ lim $b_{\text {itr, }}$ goal PPs and particles are again possible.

7 'Drinking in the dark', by Stéphan Reebs. Natural History 112(2).16, 2003 (https://archive.org/stream /naturalhistory11202unse\#page/16/; accessed October 5, 2017).

${ }^{8}$ http://www.nola.com/music/index.ssf/2013/08/ivan_neville_defines_funk_at_t.html, accessed October 1, 2017.

${ }^{9} \mathrm{http}: / /$ www.macluskie.com/reports/2014/foothillstrail_2014-05/index.html, accessed October 1, 2017.

${ }^{10}$ For the result XPs in 15, 16, 18, and 19, we conducted Google searches for plausible examples and found none. A referee suggests that what rules out 15 and related examples with intransitive climb might be the DIRECT OBJECT RESTRICTION of Levin \& Rappaport Hovav 1995:33-54, whereby result XPs may only predicate of direct objects. However, this generalization has been called into question on the basis of numerous counterexamples, many involving motion verbs; see Verspoor 1997:106-10, Wechsler 1997, and Rappaport Hovav \& Levin 2001:770-79. 
(17) a. The plaque does not explain what actually happened there; it fails to say that a UT engineering major named Charles Whitman climbed to the top of the Tower with an arsenal of weapons and opened fire on students, professors, and bystanders below. ${ }^{11}$

b. Then he climbed into the boat, and the wind stopped. ${ }^{12}$

Conversely, it is hard to find examples of other result XPs. ${ }^{13}$

(18) a. \#Being so weak from his recent illness that even the slightest physical exertion would take its toll on him, John climbed (to the top of the ladder) to exhaustion/sleep.

b. \#Thanks to his severe vertigo, John climbed (to the top of the ladder) unconscious/to unconsciousness.

c. \#John climbed (to the top of the ladder) silly/sick, having gone up so high he got dizzy.

Interestingly, $c$ limb $b_{\text {itr }}$ does allow at least some nonsubcategorized object result XPs; for example, some (but not all) speakers we consulted find the following acceptable.

(19) a. ?Moving so quickly on the rope that it cut his skin, John climbed his hands bloody.

b. ?After hours and hours of climbing, John climbed his grappling hook dull.

However, the result XP test may not tell us anything here. The point of the test is that the verb and the result XP must impose compatible constraints on their respective semantic theme arguments. But in 19, semantically speaking, the verb's theme is its subject (this is the entity that $c \lim b_{\text {itr }}$ says moves in all of its uses), but the result XP is predicated of the nonsubcategorized object, on which the surface verb imposes no constraints regarding possible changes. Thus there should be no compatibility issues (see Lupsa 2003 for a similar point with other manner-of-motion verbs; see also $\S 4$ for further discussion) ${ }^{14}$ Setting these examples aside, then, all uses of climb allow only result XPs predicating of the subject of climb that are limited to goal PPs, thus patterning like result verbs.

Although the evidence so far suggests that climb is a result verb, the two tests above are indirect: they require assumptions about correlations between entailing scalar change and the syntactic constructions a verb may occur in (object drop and resultative constructions). Ideally we would like more directly semantic evidence for entailing

${ }^{11} \mathrm{https}$ //www.texasmonthly.com/articles/fiftieth-anniversary-tower-shooting/, accessed October 10, 2017.

12 Mark 6:51, New Living Translation (accessed at http://biblehub.com/mark/6-51.htm, October 1, 2017).

13 The unacceptability of 18 might alternatively arise from a purely syntactic constraint, if $c$ lim $b_{\text {itr }}$ is unergative (consistent with being a manner-of-motion verb; see §3). Unergatives generally do not take bare result XPs (i.e. result XPs without a (nonsubcategorized) object), unlike unaccusatives. However, being a motion verb $c$ lim $b_{\text {itr }}$ would be unique among unergatives in allowing at least bare goal XPs if not other result XPs (see Levin \& Rappaport Hovav 1995:182-202 for discussion of the unusualness of motion unergatives).

${ }^{14}$ More generally, nonsubcategorized object resultatives are independently known to involve no necessary temporal integration of the event described by the verb and the change described by the result XP, which may unfold independently (Wechsler 2005:261) and even be temporally noncontiguous (Rappaport Hovav \& Levin 2001:775), suggesting that the construction describes essentially two largely separate events related loosely by causation (or possibly other relations; see Beavers 2012b:919-23 for a summary discussion). As discussed by Rappaport Hovav and Levin (2001:775-80), this also subsumes so called 'fake reflexive' resultatives (Simpson 1983:145), where the nonsubcategorized object is a reflexive referring back to the subject, and indeed for some speakers ?John climbed himself to exhaustion improves 18a despite the two changes being ascribed to the same individual. This suggests that the relevant condition for the result XP test is predication of two changes on a single syntactic argument or single individual within a single event, further arguing that nonsubcategorized object resultatives may have no bearing on the manner vs. result question, contra Rappaport Hovav 2008; see also §4. 
scalar change; we turn to this in the next section and outline several such tests, including the third diagnostic for result from Beavers \& Koontz-Garboden 2012.

2.3. THE TRUTH-CONDITIONAL UNDERPINNINGS OF SCALAR CHANGE. In order to directly test whether climb entails scalar change, we establish in more detail the truth conditions underlying scalar change. The most detailed work on this has come from the literature on lexical aspect, which has typically defined scalar change verbs as describing events whose temporal boundaries and progress are 'measured out' by the boundaries of and progress of the theme along the scale (see e.g. Tenny 1994, Krifka 1998, Hay et al. 1999, Beavers 2008, 2012a, Kennedy \& Levin 2008, inter alia). A key property of scalar change in this sense, embodied in the very name, is that there is change along a scale. Thus for any event $e$ in which there is change along a scale $s$, there must be some transition along this scale from some state $s_{i}$ to another distinct state $s_{j}$ at some point in the event. The presence of such an entailment is easily diagnosed by denying it and showing that contradiction results; for example, for change along a spatial scale the relevant test is denial of the inference that the theme is ever in a different location, as with but s/he never budged (from his/her spot). Using this, 20 verifies that move entails change along some path scale for its theme.

(20) \#Kim moved but she never budged from her spot.

(transition)

A second property of scalar change, as discussed by Beavers (2012a:32-34) in a significant revision of Krifka's (1998) analysis of motion, is that in any scalar change the event ends upon the theme reaching end state $s_{n}$, so that the end of the event is defined by a final transition along the scale. The intuition is that a scalar change predicate describes an event that is measured out by the change (as opposed to just incidentally involving scalar change at some point in the event), and thus those changes delimit the event. ${ }^{15}$ Thus if soup is being warmed from 0 to 100 degrees, upon it reaching 100 degrees it is no longer felicitous to describe the situation with the progressive form of the relevant predicate (as shown by 21 ), since it already reached that state.

(21) [Context: The soup has reached 100 degrees and is maintaining it.] \#The soup is (still) being warmed to 100 degrees. (final transition)

It might be possible in this context to say The soup is (still) being warmed (up), with no indication of a specific final temperature, if there are further fluctuations in temperature. But even in this case, once the soup reaches some final temperature and maintains it indefinitely, this too ceases to be felicitous (provided it is clear from context that no further changes are forthcoming, i.e. that this is not a temporary pause). These two properties - that there is transition at all along the scale and that the event ends on a final transition - are lexical entailments of any scalar change predicate.

A third property commonly assumed to be defining of scalar change, but which we suggest is actually independent of the two properties above, is that the final state $s_{n}$ is distinct from the initial state $s_{0}$ (see e.g. Hay et al. 1999:130-33). All verbs that have been considered in the literature on scalar change (largely canonical change-of-state verbs) have this property. For example, the patients of warm and cool must have a different temperature at the end of the event than at the beginning.

\footnotetext{
${ }^{15}$ Beavers (2012a:32-33) also assumes the event begins with an initial transition away from $s_{0}$, so that a scalar change begins when the theme makes its first transition and ends when it makes its last. However, the initial change condition is debatable; for some verbs there may be preparatory processes prior to any actual change (e.g. erecting scaffolding in building a house). Thus we set this constraint aside here. Note that continuous scalar change need not occur throughout the event; some pauses may occur, something allowed in Krifka's foundational model.
} 
(22) \#The soup just cooled/warmed and is still the same temperature it was before. (new result)

This is in fact the third and final result test from Beavers \& Koontz-Garboden 2012: 336-38. However, nothing about entailing transition and ending on a final transition necessarily requires $s_{0}$ to be different from $s_{n}$. Rather, a scalar change could in principle ultimately bring a theme back to its initial state. Thus if a new result is entailed, it is an additional, further constraint. Given this, if verbs exist that pass other scalar change tests but not this one, then previously proposed tests for scalar change are not all picking out the same notion, justifying a distinction between a general class of verbs of scalar change entailing transition and ending on a final transition and the subtype scalar result for which entailing a distinct final state holds. Standard result verbs such as cool clearly entail the stronger notion of scalar result. We suggest climb represents a case of scalar change without scalar result, albeit in different ways depending on the sense. (A further possible constraint is that the verb specify a specific directionality along the scale, as per Rappaport Hovav \& Levin 2010:29-30, 32 and Rappaport Hovav 2008:17. We argue against this in n. 21.)

First, $c \lim b_{\text {tr }+\mathrm{PP}}$ entails transitions and ending on a final transition, as shown in 23 and 24.

(23) a. \#The captain climbed the ladder down, never budging from her initial location.

b. \#The captain climbed the wall around and around, never budging from her initial location. (transition)

(24) a. \#The captain, having made it down to her room, was still climbing the ladder down.

b. \#The captain, having made it to the top of the mast, was still climbing the ladder up.

(final transition)

However, while on some uses there is also an entailment of result, as in 25a, there are uses that do not give rise to this entailment, as in $25 \mathrm{~b}$, suggesting that the scalar result entailment observed in 25a is due at least partly to the PP and not solely to the verb.

(25) a. \#The captain climbed the ladder up into the crew quarters and was in the same place she was before.

b. John climbed the wall around and around, stopping right where he began.

(no new result)

Taken together, the data suggest that in general $\operatorname{clim}_{\text {tr }+ \text { PP }}$ entails scalar change but not scalar result. If a given use of $\operatorname{clim} b_{\text {tr }+ \text { PP }}$ entails scalar result, it must be due at least partly to a specific PP such as (up) into, and around and around is not such a PP.

The situation is similar for $c \lim b_{\text {itr }}$. While $c \lim b_{\text {itr }}$ with a goal PP entails a new location, as in 26a, climb $b_{\text {itr }}$ does not entail this in all of its uses, as in 26b.

(26) a. \#Mary climbed up the ladder and was in the exact same place immediately after doing so as she was before.

b. John woke up on the mountain ${ }_{i}$ and climbed around (it ${ }_{i}$ ), eventually stopping and falling asleep in the exact same place he woke up.

(no new result)

Nonetheless, $c \operatorname{cim} b_{\text {itr }}$ does entail transitions and ending on a final transition.

(27) a. \#Mary climbed around (the mountain) all day, never budging from her spot.

b. \#Mary went to the climbing wall at her gym and climbed for four hours, never budging from her spot.

(transition) 
(28) [Context: John was climbing on a rock wall but has remained stationary for some time and it is clear he has no intention of moving further, though he is still moving his hands against the rock.]

\#John is (still) climbing (around) (on the rock wall).

(final transition)

One possible exception to the transition claim is if the theme is on an automated climbing machine - analogous to a treadmill for running — which has a moving vertical track upon which the theme can perform climbing maneuvers so as to climb 'in place'. In this case climb around is still unacceptable, as shown in 29a. However, bare climb is acceptable, as in $29 \mathrm{~b}$.

(29) a. \#John climbed around all day on the climbing machine, never budging from his spot.

b. John climbed all day on the climbing machine, never budging from his spot.

But even in 29b John arguably did move: the machine creates a virtual path and, relative to John's spot on the track the machine constructs in real time, he undergoes displacement. The virtual distance traversed is even measurable, treated linguistically like canonical change of location, as in 30a, and it must furthermore be greater than zero, as in $30 \mathrm{~b}$, suggesting transition.

(30) a. It made it to 100 degrees yesterday, so I ran 15 miles on the treadmill. ${ }^{16}$

b. \#John climbed on the climbing machine and went a total of zero meters.

Thus when climb does not imply literal displacement, it still implies relative displacement (and to the extent that 29b is acceptable, it shows that never budging from his/her spot is a blunt test, picking out only literal transitions). In sum, climb $b_{\text {itr }}$ entails scalar change but not scalar result. ${ }^{17}$

So far two senses of climb entail scalar change without scalar result, taking limited result XPs and entailing transition and ending on a final transition but not a new final location. Before we examine $c$ limb $b_{\text {tr }}$ we ask why this would be. We suggest it has to do with a key property of motion verbs, distinct from other scalar change verbs. The

\footnotetext{
${ }^{16} \mathrm{http}: / /$ slowfatmarathoner.blogspot.com/2007/08/15-miles-on-treadmill.html, accessed October 1, 2017.

${ }^{17}$ Another possible counterexample is John climbed in place in a context where John is suspended by a hook in front of a climbing wall and does climbing motions without any displacement (Chris Kennedy, p.c.), which, if acceptable, would suggest displacement is not entailed by the verb but rather arises from an interaction of what the verb does entail with particular contexts. However, our judgments and those of several other speakers we consulted is that this is unacceptable in this context, consistent with a larger subclass of mannerof-motion verbs that entail displacement, which we discuss in $\$ 3.2$ (building on Bassa Vanrell 2013, inter alia). Since our goal is to demonstrate that a class of verbs entailing scalar change without scalar result exists, this plus other verbs in $\S 3.2$ is sufficient to demonstrate that it does.

That said, other speakers we consulted found climb acceptable in this context, consistent with another subclass of manner-of-motion verbs in $\$ 3.2$ that do not entail displacement. This might suggest speaker variation in what kind of manner-of-motion verb climb is. However, this use of climb might instead be a wholly distinct sense. As we discuss in $\$ 3.1$, the manner of climb is very general, namely gravity resistance, and need not involve any particular means of this (e.g. clambering is not required as with inanimate subjects, nor even with animates: Kim climbed to 1,000 feet using a jet pack, keeping his arms and legs straight). Yet in the given context there is no gravity resistance on the part of the subject, and according to our speakers who accept it this use of climb is possible only with animate (possibly just human) subjects (e.g. \#The helicopter climbed in place at 1,000 feet in a context of a helicopter suspended in place by a crane with its propeller spinning in a manner that normally generates lift). Thus this use of climb seems to mean roughly scrabble, having a wholly distinct manner from all other climb uses, suggesting it is a wholly separate sense. It is thus unsurprising that speakers may vary as to whether they have this sense in their lexicon. (See Beavers \& Koontz-Garboden 2012:338 on manner-of-killing verbs regarding similar speaker variation in the meaning of electrocute, which for some speakers is a result verb entailing death but for others is a manner verb meaning shock.)
} 
canonical scale of change is one dimensional with a strict ordering, often with a specific directionality (see Krifka 1998:204, Zwarts 2006:18). For example, there are ordered degrees of temperature, and the scales of warm and cool reflect different directionalities along them. There is only one way to get from one temperature to another (due to the scale's being one dimensional), and thus once a transition away from some degree occurs there is only one way to return to it, by going backward. If the difference between the initial and final degrees of the theme is greater than zero, then it must be in a new state at the end of the event. These are presumably reflections of the way humans perceive physical properties such as temperature. Path scales are not like this: rather than being defined a priori, a path scale is a contextually defined construct that picks out a particular configuration of points in otherwise dense, undirected three-dimensional space relative to a given event. There are an infinite number of ways to get from any point to any other in space, and furthermore one can leave a location and return to it without ever technically backtracking (save for the final moment of reentering the prior location) by going in an arc that consists of continuous forward motion that just happens to ultimately double back (see e.g. Krifka 1998:224-25, Zwarts \& Winter 2000: 202-3, Zwarts 2003, 2005:749-50).

This is demonstrated by the fact that measure phrases for path scales behave differently from those of other scales. Consider the data in 31.

(31) a. Kim warmed the soup ten degrees.

b. Kim walked ten miles.

Example 31a can only describe an event where the soup is ten degrees warmer at the end of the event than at the beginning. It cannot describe a situation in which the cumulative change was ten degrees but the actual new temperature is less than ten degrees above the initial temperature. Suppose Kim heats the soup up six degrees and then lets it cool four degrees to ultimately be two degrees warmer than it started out. Here the soup traversed a total of ten degrees (six up and four down), yet 31a is false. Conversely, $31 \mathrm{~b}$ allows such a reading; for example, it is felicitous if Kim walks five miles north and then back five miles south, or does a ten-mile arc, returning to the original location and determining a displacement in initial and final positions of zero miles. Thus spatial paths are measured differently from other scales: the unfolding of the path allows continuous progress after leaving the initial point to count as 'forward' progress for purposes of measurement, even if looping occurs.

For $c \lim b_{\text {itr }}$ and $c \lim b_{\text {tr }+ \text { PP }}$ the possibility of looping is sufficient to derive scalar change without scalar result: the only condition of the verb is movement along a path, not that the path does not double back on itself. Evidence for the significance of looping in deriving scalar change without scalar result can be seen by looking finally at $c$ limb $b_{\text {tr }}$. At first blush, climb tr differs from the other senses, entailing not just transitions and ending on a final transition, as in $32 \mathrm{a}$ and $32 \mathrm{~b}$, respectively, but also that at the end of the event the theme is somewhere different from at the beginning, as in $32 \mathrm{c} .{ }^{18}$

\footnotetext{
${ }^{18}$ Uses of $_{\text {climb }}$ tr with for an hour modifiers (which are attested but difficult to find) might suggest $c l i m b_{\text {tr }}$ does not entail a new final state. Although we and others we have consulted find (i) unacceptable, a minority accept it.
}

(i) We climbed the wall for an hour or so.

(http://www.barelybeacon.com/the-great-wall/, accessed October 1, 2017)

If $\operatorname{climb} b_{\text {tr }}$ entails a result, it should head an accomplishment (modulo bare plural or mass theme DPs). Accomplishments normally do not take for PPs, but do when the reading is coerced to an activity, which Krifka (1998:215) analyzes as imperfective or iterative coercion, de Swart (1998:361-62) by an operator that turns 
(32) a. \#Kim climbed the ladder, never budging from her spot. (transition)

b. \#Having completely stopped and with no intention of moving again, Kim is (still) climbing the ladder.

(final transition)

c. \#Kim climbed the ladder and was in the exact same place immediately after doing so as she was before.

(new result)

Thus $c$ limb $b_{\text {tr }}$ appears to be a scalar result verb, having all three properties, like cool or warm.

However, as Chris Kennedy (p.c.) points out, there are contexts allowing a felicitous use of climb $_{\text {tr }}$ in which a new result does not obtain, in particular in M. C. Escher's famous lithograph Ascending and descending, where a set of Penrose stairs loops back on itself while still going 'up' through tricks in perspective. In this context 33 is acceptable.

(33) Kim climbed the stairs and was in the exact same place immediately after doing so as she was before.

The fantastical context is key-normally upward movement along a complete path precludes looping. But in this context it does not, and the acceptability of 33 shows that $c l i m b_{\text {tr }}$ does not actually entail scalar result; it only followed in $32 \mathrm{c}$ due to the nature of upward-directed paths in the real world. The minimal contrast in the interpretation of $c l i m b_{\text {tr }}$ that hinges on the possibility of looping motivates looping as sufficient to ex-

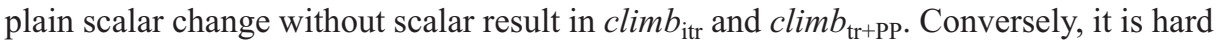
to envision a fantastical context for canonical result verbs like cool that would permit looping, explaining why these verbs do entail scalar result.

In summary, while no sense of climb entails scalar result, they all entail scalar change without scalar result, though in the case of $\operatorname{clim} b_{\text {tr }}$ the nature of complete traversal of the path plus upwardness ensures that a new result obtains in ordinary real-world contexts, if not Escher contexts. This contrasts with cool or warm, which do entail scalar result. In the next two sections we discuss further evidence for the claim that climb entails scalar change in all of its uses by examining additional properties of scalar change from the formal semantic literature on lexical aspect.

2.4. AdDITIONAL EVIDENCE FOR SCALAR CHANGE: QUANTIZED VS. NONQUANTIZED CHANGE. One major distinction among scalar change verbs is the difference between predicates that entail quantized vs. nonquantized change (Hay et al. 1999, Beavers 2011b), usually defined as whether the new state entailed by the verb is a specific state, as with break, where the final state is brokenness, or just any new nonspecific state, as with $\mathrm{cool}$, where the final state is any lower temperature than before (even if made specific in context). This distinction is relevant for whether a predicate is telic (quantized change) or atelic (nonquantized change) (ignoring the independent effects of bare plural or mass theme arguments; see Beavers 2012a for discussion). Thus predicates headed by break and cool (on its nonquantized use) differ in their telicity, but both still entail scalar result.

(34) a. The vase broke in five minutes \#and it's the same as it was before.

b. The soup just cooled for five minutes \#and it is still the same temperature it was before.

events into homogeneous processes, and Rothstein $(2004: 114-15,190-91)$ by an operator that detaches the activity inherent in an accomplishment from the change. Thus the lack of a result in (i) is expected for independent reasons and does not argue against the classification of such predicates as accomplishments. Coercion also explains why one speaker we consulted found The children climbed the jungle gym acceptable (also noted by Levin \& Rappaport Hovav 2013:65, though we find it unacceptable) in the context of children performing standard playing activities normally associated with a jungle gym — exactly the reading Rothstein predicts - although the default reading is still upward complete traversal. 
Thus the quantized vs. nonquantized distinction crosscuts scalar result verbs, though verbs like break entailing exclusively quantized change are the canonical result verbs, with the strongest entailment of a new result state (see Beavers 2011b).

It turns out, however, that despite being a scalar change verb that does not entail scalar result, $c$ limb $b_{\text {tr }}$ is unlike the other senses of climb in one respect: as discussed in $\S 2.1$ for $5 \mathrm{a}$, there is a requirement that the theme reach the end of the path denoted by the object (or close to it), as with traversal objects in general, something that holds in both the real world and Escher contexts.

(35) \#Kim climbed the stairs, but only made it two steps before giving up. [=5a] In other words, $c$ limb $b_{\text {tr }}$ entails that the theme reach a specific point situated (roughly) the full distance along the path, which in normal contexts is a new location but in a fantastical context might not be. Reaching a specific state (or having the final state derived by a specific difference degree from the initial state) is the essence of quantized change, suggesting that $c l i m b_{\text {tr }}$ is a quantized scalar change verb despite not being a scalar result verb, a surprising observation given the understanding of quantized scalar change verbs as result verbs par excellence. This is distinct from the other two uses of climb, where there is no particular place the theme must end up. Thus the other two senses of climb entail nonquantized scalar change - the theme must reach some location, though again the theme's ultimate location could be the initial location. Crucially, that there is evidence of a quantized vs. nonquantized distinction among the senses of climb further motivates there being scalar change in its meaning, since the distinction itself presupposes scalar change.

2.5. AdDitional EVIDENCE FOR SCALAR CHANGE: ASPECTUAL DiAgnostics. Climb also patterns like canonical scalar change verbs in terms of durativity properties. In particular, as discussed in Beavers 2008, the durativity of scalar change predicates is contingent (partly) on the interpretation of the underlying scale: nongradable (two point) scales yield punctual predicates, and gradable (more than two point) scales yield durative predicates (provided the theme is not interpreted as being mereologically complex in ways that generate a type of iterative interpretation; see Beavers 2012a for discussion). Thus in 36 with the telic predicate cross $X$, a short path yields a punctual reading and a long path a durative one, evidenced by the fact that a temporal in modifier is possible only on an 'after' reading with the short path, but has both an 'after' and 'during' reading with the long path (standard tests for punctuality and durativity, respectively; Kearns 2000:206).

(36) a. The woman will cross the border in five minutes.

b. The woman will cross the desert in five days.

(after/during)

Similarly, telic climb predicates allow a punctual reading if the path is interpreted as short and a durative reading if long, for any use of climb.

(37) a. [Context: John is standing just next to a single stair.] John will climb (up) the stair (to the next level) in five minutes.

(after)

b. [Context: John is standing at the bottom of a long staircase.]

John will climb (up) the stairs (to the attic) in five minutes. (after/during)

Thus path length and durativity of telic climb predicates correlate, as with canonical scalar change.

The interpretation of in modifiers is inapplicable with atelic climb predicates since atelic predicates prefer for modifiers. However, even here there is evidence of scalar change. In particular, for PPs require durativity, and if climb entails scalar change, then just as scale length should affect durativity, durativity should affect the interpretation of 
the scale length, even absent an overt path XP (see e.g. Beavers 2008:253-54). This is borne out, as atelic climb predicates with for PPs are not acceptable in contexts with a short path qua nongradable scale such as one with one step (which is normally conceived of as short, though specialized contexts might yield coercion to a longer path; see Beavers 2012a:47, n. 14, 50-52, and Bassa Vanrell 2013:66-71 for discussion).

(38) a. John climbed around (the mountain) for five hours, \#moving exactly one step over that course of time.

b. John climbed for one hour, \#moving exactly one step over that course of time.

Taken together, the correlations of durativity to path length in both telic and atelic uses of climb are additional independent evidence that climb entails scalar change. ${ }^{19}$

2.6. Summary AND INTERIM CONCLUSION. Taking stock, the question of whether climb entails result is not about upwardness but about scalar change. Focusing on this, all uses of climb pass nearly all diagnostics that have been previously applied to canonical scalar change verbs like break and cool, including direct semantic properties from formal semantic work on scalar change (aspectual and inferential properties) and indirect syntactic tests discussed in work on manner/result complementarity. These include (i) entailing transitions along a scale during the event, (ii) entailing that the event end on some final transition, (iii) a correlation of durativity to scale length, and (iv) restrictions on possible result XPs. Among the verbs that pass those tests, however, we see (at least) two major crosscutting distinctions: (i) whether the theme is entailed to reach a specific point along the scale during the event (quantized change) or not (nonquantized change), and (ii) whether a new result state is entailed (scalar result) or not (simple scalar change). These two crosscutting distinctions generate the typology in Table $1 .{ }^{20}$

\begin{tabular}{|c|c|c|}
\hline \multirow{5}{*}{ QUANTIZED CHANGE } & \multicolumn{2}{|c|}{ SCALAR CHANGE } \\
\hline & SCALAR RESULT & UNSPECIFIED FOR SCALAR RESULT \\
\hline & New result entailed & No new result entailed \\
\hline & Specified state reached & Specified state reached \\
\hline & (e.g. break) & $\left(\right.$ e.g. $\left.\operatorname{clim}_{\mathrm{tr}}\right)$ \\
\hline \multirow{3}{*}{ NONQUANTIZED CHANGE } & New result entailed & No new result entailed \\
\hline & No specified state reached & No specified state reached \\
\hline & (e.g.cool) & (e.g. climb $_{\mathrm{tr}+\mathrm{PP}} /$ climb $\left._{\mathrm{itr}}\right)$ \\
\hline
\end{tabular}

TABLE 1. Typology of change.

What does this new classification mean for the notion of result verb and diagnostics for such verbs? Interestingly, nearly all previously proposed result tests actually pick

\footnotetext{
${ }^{19}$ Additionally, scalar change also figures into whether a verbal predicate is telic (e.g. Krifka 1998, Hay et al. 1999, Beavers 2012a). However, as noted above, scalar change predicates can be either telic or atelic, and thus telicity is not a useful test for whether a verb entails scalar change (see also Rappaport Hovav \& Levin 2010:27)

${ }^{20}$ So far, all of the examples of scalar change verbs that are not scalar result verbs come from the domain of motion, where such verbs are natural for reasons to do with looping in their scales, as discussed above. However, we do not rule out the possibility that nonmotion verbs may also fall into this category. In particular, Zwarts (2008:99) notes that semelfactives like cough, flash, and knock have a similar 'event shape' (qua abstract path; see Zwarts 2006) to his 'cycle' motion predicates with prepositions like over or around, which consist of entering a region and then leaving it again in ways that can be iterated, resulting in looping. The question would be whether Zwarts's 'event shape' is analogous to a scale in the sense typically used so that semelfactives could be argued to be scalar (see e.g. Beavers 2013 for an analysis of semelfactives as nonscalar). We remain agnostic as to this point, leaving it for future research.
} 
out the broader notion of scalar change rather than the more narrow notion of scalar result (and we suggest in $\$ 3.2$ that object drop also identifies scalar change more generally). Only the entailment test for a new result uniquely picks out scalar result verbs. Thus, previously discussed diagnostics were not all picking out the same thing, and most arguments based on them were targeting a broader class of verbs than expected. This classification has similar consequences for how one identifies quantized scalar change in a verb's meaning. One test (see Beavers 2011b) is that a specific new state be named that cannot be denied, but in light of the above a better test is whether the theme must move a particular distance from its initial state (e.g. \#John climbed the stairs, but never reached the end), even if it arrives back at its original state. Similarly, in a looping context telicity need not obtain; for example, Kim climbed the stairs for two hours is fine in the Escher context, and does not feel (to us) like aspectual coercion, as per $\mathrm{n}$. 18. Rather, looping can just go on indefinitely. This suggests that telicity is simply not a good test for quantized change in general (contra Beavers 2011b). In short, the key result is that there are verbs that do not match the intuitive definition of a result verb yet still entail scalar change, even showing the same subtype distinction between nonquantized and quantized change as canonical result verbs, a distinction that itself suggests the verbs entail scalar change. ${ }^{21}$

In the next three sections we explore various further consequences of the more nuanced understanding of result verbs presented in Table 1, beginning with the question of how well attested scalar change verbs that do not entail scalar result like climb are: is climb just a unique case that can be treated as exceptional and largely ignored, or is it representative of a larger class? We suggest the latter is true, and climb is just one representative of a broader set of scalar change verbs found within the class of motion verbs more generally and specifically within the class of manner-of-motion verbs. This in turn leads to the consequence that the class of manner-of-motion verbs is not as uniform as previously thought, and also does not cleanly contrast with path verbs, contra most work on motion typology. We also demonstrate that manner-of-motion verbs entailing scalar change form a linguistically significant subset of scalar change verbs in terms of some of the result tests discussed above. As a prelude to these observations, we first clarify that climb is in fact categorically a manner-of-motion verb.

3. CONSEQUENCES FOR MOTION TYPOLOGIES: MANNER-OF-MOTION VERBS AS SCALAR CHANGE VERBS. Levin and Rappaport Hovav (2013:58) classify climb as a manner-ofmotion verb, but propose that when it entails scalar change the manner component is dropped, consistent with manner/result complementarity. We argue that climb in fact

\footnotetext{
${ }^{21}$ As mentioned in \$2.3, Rappaport Hovav and Levin (2010:29-30, 32) and Rappaport Hovav (2008:17) suggest that entailing a specific direction of change along the scale is also a prerequisite for being a scalar change verb; cross the river, for example, does not and thus is not a scalar change verb (though there is directionality in the sense of moving away from the theme's initial position, the reference point as per Rappaport Hovav 2014:267-73, so it is not clear that this claim is justified). However, we see no evidence that directionality matters for entailing scalar change, since directionality is entirely orthogonal to every other defined property of scalar change verbs. For example, nondirected verbs like cross entail a new result, transitions, or ending on a final transition, have path/durativity correlations, and take limited result XPs (e.g. The hiker crossed the river to the other side/*to exhaustion). We thus see no reason to assume that entailing direction is linguistically significant for the relevant issues and so set it aside, instead agreeing with Rappaport Hovav $(2014: 266,272)$ that a verb can lexicalize scalar change even if it does not specify every single aspect of the scale's structure.
} 
entails manner in all of its uses, opening up the possibility that other manner-of-motion verbs may entail scalar change, which we also demonstrate.

3.1. Climb IS A MANNER Verb. The traditional view is that the manner of climb is clambering (Jackendoff 1985:276 and Kiparsky 1997:490-91). Geuder and Weisgerber (2008, slides 91-171) and Levin and Rappaport Hovav (2013:59-61) argue against this, since climb allows inanimate themes that cannot clamber.

(39) a. The plane climbed to cruising altitude.

b. The train climbed down the hill.

Geuder and Weisgerber (see also Jackendoff 1985:283-84) argue that the manner climb entails is 'force exertion against gravity', in other words, a tendency for the theme to resist or defy gravity ('the presence of an upward force on certain points of the path'; Geuder \& Weisgerber 2008, slide 26). Absent this, ascent or descent cannot be described as a climbing, as evidenced by $40 .{ }^{22}$

(40) a. \#The train climbed down the mountain, tumbling end over end the entire way.

b. [Context: A ladder is in outer space and two astronauts are doing a spacewalk at its foot, so that just a push will cause an astronaut to head up the ladder.]

\#After her colleague gave her a shove, the astronaut climbed the ladder, staying still and doing nothing as she went up.

The crucial question is whether gravity resistance is present in all uses of climb. Based on data such as 41, Levin and Rappaport Hovav (2013:65-66) claim that it is not.

(41) a. The prices/cost climbed.

b. Despite the new measures, the inflation/unemployment rate climbed.

c. During the recession, the number of foreclosures climbed.

(ibid., p. 66, ex. 36)

Levin and Rappaport Hovav (2013:66) note that since the themes in 41 are abstract, there can be no manner. Instead the themes represent attributes of an entity on a scale, and climb here means that the value for that entity increases on the scale, a type of figurative upward motion. Thus climb is normally a manner verb, but the manner component can be dropped in favor of scalar change. ${ }^{23}$

While we agree that the examples in 41 are figurative, we disagree that gravity resistance is inapplicable. First, there are figurative examples with overt reference to gravity, as in 42 , with $42 \mathrm{~b}$ involving climb.

(42) a. Once again US core CPI inflation defied gravity with a rise of just $0.1 \%{ }^{24}$

b. Oil prices defy gravity, $\$ \mathbf{9 9}$ ?

Crude oil prices continued their climb toward \$100 (€67) a barrel slowly but surely, in a surge that threatens developing economies such as Turkey. ${ }^{25}$

\footnotetext{
${ }^{22}$ In light of examples involving outer space, Levin and Rappaport Hovav (2013:60, n. 4) suggest that the relevant force may not technically be gravity but something more general, but we set this aside for present purposes.

${ }^{23}$ If figurative uses are metaphors, then this argument assumes that metaphoric extensions of words must preserve all aspects of meaning, something not always assumed, as per Lakoff 1990 (see also Croft \& Cruse 2004:201), though since Levin and Rappaport Hovav's argument hinges on it, we assume so for the sake of argument.

${ }^{24} \mathrm{https} / / /$ www.rbccm.com/economics/file-434146.pdf, accessed October 14, 2014.

${ }^{25} \mathrm{https} / /$ www.icis.com/resources/news/2007/11/23/9081099/in-friday-s-europe-papers/, accessed October $1,2017$.
} 
These data suggest that (figurative) gravity is in principle applicable to abstract themes, opening up the possibility that it is applicable to 41 as well. Second, even absent overt reference to gravity, in 41 there is a sense that the increase is against some established tendency to either not go up or to go up at some slower rate, analyzable as figurative gravity. That figurative climb conveys this notion can be illustrated by establishing a particular gravity in a particular context and comparing uses of climb in that context to rise or increase, which we assume are neutral to gravity resistance and entail just upwardness, following Geuder and Weisgerber (2008, slides 172-203).

Suppose there is an expectation that the price of a cup of coffee will increase by $10 \varnothing$ a year, and this is the only expected increase; in other words, this is considered a reasonable or normal rate and no other rates are expected. (If it were considered abnormal it could only be because there was some other expectation about increases in prices of cups of coffee.) This rate establishes the figurative gravity for any actual change in the price of a cup of coffee. Subsequent observed increases that are below, in line with, or exceeding that rate can all be described by rise and increase, whereas climb is acceptable only if the increase defies the expectation-in other words, it resists established figurative gravity.

(43) We expected the price of a cup of coffee to go up at the reasonable rate of $10 \varnothing$ a year

a. ... but instead it rose/increased/\#climbed by $1 \varnothing$ a year.

b. ... and indeed it rose/increased/\#climbed by $10 \notin$ a year.

c. ... but instead it rose/increased/climbed by $\$ 2$ a year.

This suggests that there are expectations built into climb about resistance to (figurative) gravity.

However, it is important to establish exactly what the relevant expectations are, since there could be multiple expectations climb is sensitive to. Consider a context where the price of a cup of coffee would normally increase at a reasonable rate of $10 \notin$ a year, but due to other economic factors there is an expectation that this year it will instead increase by $\$ 2$. Here there are two expectations. In this context any increase over the baseline expectation of $10 \notin$ a year can be described by climb, including one in which the actual increase was less than $\$ 2$ a year or more, but not an increase at or below the baseline of $10 \notin$ a year, whereas rise and increase are always acceptable.

(44) We expected the price of a coffee to increase at the outrageous rate of $\$ 2$ a year, instead of the reasonable rate of $10 \notin$ a year,

a. ... but instead it rose/increased/\#climbed by only $5 \phi / 10 \phi$.

b. ... but instead it rose/increased/climbed by $\$ 1 / \$ 3$.

c. ... and indeed it rose/increased/climbed by $\$ 2$.

In other words, the relevant figurative gravity for climb is whatever is considered a baseline in context; other expected rates of change may not figure into its felicity.

This explains naturally occurring data such as 45 , where climb occurs with a modifier indicating an increase below expectations.

(45) Euro Zone inflation in May climbed slower than expected at $2.7 \mathrm{pct} y / \mathrm{y}$. The marekt [sic] expected the consumer prices to rise 2.8 pct in April [sic], after rising 2.8 pct in April. ${ }^{26}$

26 https://www.mt5.com/forex_news/quickview/1148840-euro_zone_inflation_in_climbed_slower_than _expected_in_may/, accessed October 1, 2017. 
Crucially, while the increase is below the stated expected increase of $2.8 \%$, the use of climb (as opposed to increase or rise) in 45 conveys that even $2.8 \%$ is considered to defy some other implicit (lower) gravity. The same passage with increase or rise does not give rise to an expectation that there was any expected gravity other than the one stated.

(46) Euro Zone inflation in May increased/rose slower than expected at 2.7 pct $\mathrm{y} / \mathrm{y}$. The market expected the consumer prices to rise $2.8 \mathrm{pct}$ in May, after rising 2.8 pct in April.

Here the only expectation is from the linguistic context immediately following the verb. Levin and Rappaport Hovav's figurative examples in 41 have a gravity-defying flavor as well, and in $41 \mathrm{~b}, \mathrm{c}$ there is furthermore explicit reference to gravity-defying circumstances (the failure of economic measures and an economic recession, respectively). In light of all of this, gravity is as applicable to abstract themes as to concrete ones, and the examples in 41 involve no special use of a mannerless climb.

Thus climb does seem to entail manner, and given this we furthermore expect that climb should pass typical manner diagnostics. ${ }^{27}$ Beavers \& Koontz-Garboden 2012: 343-49 outlines three such tests. First is whether there is a noncancelable inference that the manner occurs, in this case resistance to gravity. The data just given illustrate this. Second is that the manner may restrict possible subjects, where only those whose referents are independently capable of defying gravity should be possible. This seems to be the case: for example, instrument subjects (Fillmore 1970:122-24) that are otherwise incapable of defying gravity on their own are impossible with any sense of climb.

(47) a. John climbed (the mountain) (down to the bottom) with a grappling hook/a rope.

b. \#The grappling hook/the rope climbed (the mountain) (down to the bottom).

A third test involves durativity, where some manners force a predicate to be durative even if the scale is nongradable. This test is inapplicable to climb, since defying gravity does not require any particular action. Nonetheless, the totality of the evidence suggests that climb categorically entails manner, justifying its classification as a manner-ofmotion verb. We next show that other verbs in the class of manner-of-motion verbs are like climb in entailing scalar change, meaning climb is not an isolated example. This observation in turn bolsters the argument that the analysis of climb as entailing both manner and scalar change is correct by showing that it is not an isolated example.

3.2. BEYOND climb: OTHER MANNER-OF-MOTION VERBS ENTAIL SCALAR CHANGE. In work rooted in the Talmy typology, manner-of-motion verbs contrast with path verbs, which encode the path along which something moves, but not the manner in which it moves, a distinction that can be viewed as the manner vs. result distinction manifested in the domain of motion (see e.g. Rappaport Hovav \& Levin 2010:27). Yet if at least some subset of manner-of-motion verbs are scalar change verbs, then the distinction between path verbs and manner verbs breaks down. We argue that there are other mannerof-motion verbs that also entail scalar change, and thus have a path as part of their meaning (echoing ideas indirectly suggested in Beavers 2012a; see also Zlatev \& Yangklang 2004 on manner + path verbs in Thai), taking as our evidence the scalar

\footnotetext{
${ }^{27}$ Rappaport Hovav and Levin (2010:38, n. 8) also discuss soar and suggest that its apparent gravity-defying manner is an implicature derived from describing traversal of large scalar distances. This will not explain climb, which is compatible with short distances (e.g. Prices climbed/??soared by 1 \& despite expectations that they would stay static).
} 
change diagnostics in $\S 2$. These conclusions ultimately lead us to propose a richer typology of manner-of-motion verbs than previously acknowledged. (For the verbs discussed in this section we take their manner entailments to be uncontroversial and thus do not provide evidence for them.)

There are already known to be multiple types of manner-of-motion verbs. For example, Bassa Vanrell (2013:36-37) argues that there are three subclasses in Spanish based on what they imply about displacement of the theme: (i) those that neither entail nor implicate displacement, (ii) those that do not entail but implicate displacement, and (iii) those that entail displacement; we believe this classification holds in English as well, focusing on the verbs in 48. (For similar observations see Cummins 1996:38 and Fábregas 2007:185-86. See also Jones 1996:396 and Bassa Vanrell 2013:33-34 on manner-ofaimless-motion verbs equivalent to wander or mosey, which also require displacement, and Folli \& Ramchand 2005:11-15, Folli \& Harley 2006:143-44, and Son \& Svenonious 2008:392, 395, inter alia, for additional related discussion.)

(48) a. Displacement not expected: dance, float

b. Displacement expected but not entailed: run, jog

c. Displacement entailed: slide, ski, roll, drag

Bassa Vanrell's test is whether each verb is acceptable with modifiers meaning roughly 'in place' or 'without leaving his/her spot'. Dance-type verbs are acceptable out of the blue with such modifiers, as in 49a, while run-type verbs sound odd with such modifiers out of the blue, as in $49 \mathrm{~b}$, but are fine in particularized contexts (e.g. making running motions while waiting at a sidewalk for a light to change; see also Rappaport Hovav 2014:262). Slide-type verbs, by contrast, are unacceptable with such modifiers altogether, regardless of whether the verb is intransitive and the subject is the theme, as in $49 \mathrm{c}$, or transitive and the theme is the object, as in $49 \mathrm{~d} .^{28}$

(49) a. John danced/floated in place/without leaving his spot.

b. John ran/jogged in place/?without leaving his spot. (fine in some contexts)

c. \#John slid/skied/rolled in place/without leaving his spot.

d. \#John slid/rolled/dragged the logs without them leaving their spot.

Furthermore, these judgments seem sharp even in contexts in which the theme is somehow suspended in place and manners of the appropriate sort are being practiced (see $n$. 17). ${ }^{29}$ Crucially, undergoing displacement is one of the tests for scalar change, suggesting that the verbs in 50c,d may be scalar change verbs (contra Rappaport Hovav 2014: 273-78).

\footnotetext{
${ }^{28}$ An exception might be made for cases where a given action is performed on some sort of machine with a moving element to it-for example, if it were possible for one to ski in place on a treadmill.

(i) After my warm-up I stepped onto the NordicTrack ... I skied in place for about three more songs before I remembered another reason I hate working-out - the sweat. (http://www.chetekalert.com/article_\%20ee6b96b9-ce83-5ae6-8e70-f5637b82c412.html, accessed October 1, 2017)

However, as noted for climb in $\S 2.2$, there is still displacement in relation to the moving track; in other words, there is still scalar change.

${ }^{29}$ A referee asks specifically if a ball or wheel somehow suspended in and rotating in water might not be said to be rolling. Our judgment is that this is not possible as per n. 17, unless the water is moving underneath it in a way that reduces to a treadmill-type situation, as already discussed above. For some speakers, however, roll may have a truly nontranslational meaning like spin and is acceptable in sentences like $49 \mathrm{c}, \mathrm{d}$, though these are not our judgments. Here we just discuss speakers who have a distinction between roll and spin (the Oxford English Dictionary lists both meanings separately).
} 
A second test is that the event ends on a final transition, and again the verbs in question are unacceptable if the movement has stopped and no further movement is forthcoming.

(50) a. \#John is (still) sliding/skiing/rolling.

b. \#John is (still) sliding/rolling/dragging the logs.

(in given context)

Furthermore, there are length/durativity correlations. Predicates projected by these verbs are typically atelic, and with for modifiers on a necessarily durative reading a trivially short path is ruled out, just as with atelic climb predicates in $\S 2.5$.

(51) a. ??John slid/skied/rolled for five minutes, barely moving just one millimeter.

b. ??John slid/rolled/dragged the logs for five minutes, barely moving them just one inch.

However, it is not a requirement that the final location be distinct from the initial location.

(52) a. John slid/skied/rolled, ending up in the exact same spot as he started out in.

b. John slid/rolled/dragged the logs, stopping when they were in the spot they started in.

All together, the semantic evidence suggests these verbs entail scalar change, but not scalar result.

This is corroborated by more indirect result tests from $\$ 2.2$, such as theme objectdrop. Here intransitive verbs or those with traversal objects are irrelevant, since their themes are their subjects. But for theme object verbs the test applies, and in some object drop is disallowed, as with drag.

(53) a. John dragged the logs.

b. *All last night, John dragged.

In other cases (slide and roll) object drop seems to be possible, but crucially gives rise to a significant meaning shift wherein the subject is interpreted as the theme rather than the dropped object.

(54) a. John slid/rolled the coin.

b. All last night, John slid/rolled. (does not mean John slid/rolled something)

This suggests that $54 \mathrm{~b}$ does not show object drop but instead the inchoative counterparts of the causative uses of these verbs (Levin \& Rappaport Hovav 1995:110-19). ${ }^{30}$ These data thus suggest again that certain manner-of-motion verbs entail a scalar change (and that the object-drop test picks out simple scalar change verbs). The other, more indirect test is the result XP diagnostic. It turns out the data with this are more complicated, albeit in ways that ultimately support and expand on the conclusions we have outlined here; we return to this in more detail in $\S 4$.

So far it appears that the division between path verbs and manner-of-motion verbs is blurred: some manner-of-motion verbs, like canonical path verbs, entail scalar change. ${ }^{31}$ Of course, if it is motion itself that allows for scalar change without scalar result via looping, as discussed in $\S 2.3$, we would expect even canonical path verbs to allow this, and

\footnotetext{
${ }^{30}$ Intransitive roll has an independent use meaning 'go bowling' that is not relevant here. Thanks to Jacques Lafleur for pointing this usage out to us.

${ }^{31}$ One way to save the traditional dichotomy would be to assume, like Zubizarreta and Oh $(2007: 139,206$, n. 11), that the displacement entailment in verbs like climb and slide does not come from the verb but from a phonologically null preposition, with the verb only introducing manner entailments (as a modifier of a light verb in the event structure). Such an analysis would, however, have to explain why the null preposition is obligatory with these verbs.
} 
this does seem to be the case. Both circle and generic translational move also pattern with scalar change verbs but not scalar result verbs.

(55) a. \#John moved, but didn't leave his spot.

(transition)

b. \#John is (still) moving, but will not budge another inch.

c. John moved, and ended up in the exact spot he started.

(56) a. \#The wolves circled me, but didn't leave their spot.

(final transition)

(no new result)

b. \#The wolves are (still) circling me, but will not budge another inch.

(final transition)

c. The wolves circled me, and ended up in the exact spot they started.

(no new result)

Note that circle entails quantized scalar change- the theme must complete a circle (more or less; Zwarts 2003, 2006:3-4), while move does not-movement to any location satisfies its lexical entailments. We thus derive a typology of motion verbs that goes above and beyond the standard manner vs. path verb distinction, with there being verbs that have mixed properties; see Table 2.

\begin{tabular}{lll} 
& \multicolumn{1}{c}{ - MANNER } & \multicolumn{1}{c}{ +MANNER } \\
-SCALAR CHANGE & N/A & run, jog \\
+SCALAR CHANGE (nonquantized) & move & ski, roll, drag, slide, climb ${ }_{\text {itr }}$, climb $_{\text {tr }+ \text { PP }}$ \\
+SCALAR CHANGE (quantized) & circle & climb $_{\text {tr }}$
\end{tabular}

TABLE 2. Typology of motion verbs.

Motion verbs without manner are canonical path verbs, and those with manner but no scalar change are canonical manner verbs, but the existence of classes with both complicates the clean, dichotomous view of these verb classes common in the literature, and superimposing the crosscutting nonquantized vs. quantized distinction suggests an even richer typology. (We are unsure if there are motion verbs that entail scalar result as well, which looping may preclude altogether. We leave this possibility open.) This in turn may have consequences for proposals that have assumed a simple dichotomy. For example, it is often assumed that the decompositional event structures of manner and path verbs differ significantly, based on basic ACT vs. BECOME or GO primitives, respectively (see e.g. Inagaki 2002, Mateu \& Rigau 2002, Folli \& Ramchand 2005). It is an open question what the relevant event structures are for mixed verbs (though see Beavers \& Koontz-Garboden 2012 for some discussion of this question in semantic domains other than motion), but the existence of them certainly complicates any clearly dichotomous view of the event structures of manner and path verbs. Likewise, works rooted in the Talmy typology have proposed significant generalizations about how manner and path verbs combine with goal expressions across languages (see Beavers et al. 2010 for an overview); the existence of mixed classes may require revisiting these constraints (see Tham et al. 2012, and Bassa Vanrell 2013 for some discussion). Finally, languages with different basic Talmyan types also tend to have lexicons that favor the particular type (e.g. path languages tend to have more diversity in path verbs than manner verbs and vice versa; Wienold 1995, Slobin 1996, inter alia). The diversity of types of motion verbs in Table 2 raises the question of how verbs that have elements of both are distributed (see Zlatev \& Yangklang 2004 for observations on this in Thai). These are all questions for future work, but they suggest the kinds of ramifications the observations made here will have for motion typologies. We next consider the special status of manner-of-motion scalar change verbs and show that the presence of manner in their meaning (among other things) complicates how the result XP diagnostic is to be applied, motivating the hypothesis that these verbs form a distinct subclass of scalar 
change verbs that is linguistically significant in terms of the types of grammatical constructions they can occur in, while also clarifying the nature of the diagnostic itself.

4. FURTHER MOTIVATION FOR A REVISED MOTION TYPOLOGY AND CONSEQUENCES FOR RESULT DIAGNOSTICS. In $\S 2$ we noted that previous diagnostics for result-and scalar change in general - are complicated by the new verb-class typologies we have outlined: different result tests picked out distinct notions of result, and tests of nonquantized vs. quantized change were too narrowly defined. In this section we consider some deeper problems that may arise by looking in more detail at the result XP test. This test turns out to not behave uniformly with the verbs discussed in $\$ 3.2$, which we argue reflects the fact that there is more nuance to it than previously thought: while the test was previously assumed to be sensitive solely to the presence of scalar change in the verb, other factors are relevant as well, including the verb's inherent argument structure, subtleties of the compatibility of the verb and result XP's entailed scalar changes, and the presence of manner in the verb in addition to scalar change. This last fact suggests that manner-of-motion verbs that entail scalar change are not just verbs that happen to have both meaning components at once; the combination is linguistically significant among scalar change verbs in the sense of having a unique set of behavioral patterns vis-à-vis standard result tests. Crucially, these factors are obvious only if one has first identified a class of scalar change verbs that also entail manner.

We first outline the basic patterns of result XPs with manner-of-motion verbs. First and foremost, some intransitive manner-of-motion verbs allow nonsubcategorized objects with a wide range of result XPs (though it is difficult to find naturally occurring examples).

(57) a. The skiers skied the trail clean of snow.

b. The skiers skied their skies to pieces.

c. The skiers skied their toes raw.

As noted in $\$ 2.2$, however, this does not tell us anything; the result XP and the verb are predicating scalar change of different themes, and thus even if the verb does entail scalar change on its own, no incompatibility should arise. Given the generality of this, it suggests our first qualification for the diagnostic: it is applicable only if the result XP is predicated of the semantic theme argument DP of the main verb, and thus nonsubcategorized object resultatives are not relevant (see n. 14). However, nonsubcategorized object resultatives are also not typically found with canonical change-of-state verbs, instead being largely limited to intransitives that entail manner (e.g. unergatives; Simpson 1983:145-46). To put it another way, nonsubcategorized object resultatives do not distinguish scalar change verbs from others: they are acceptable with any intransitive manner-entailing verb regardless of whether it also entails scalar change. It just took finding verbs like motion verbs entailing both a manner and a change in the subject for this to be apparent.

Bearing this in mind, the results of the diagnostic when directly applicable are still complex. Goal PPs are acceptable and widely attested with the relevant intransitive manner-of-motion verbs.

(58) a. I went there to get my ski pass then got myself to the top of the mountain, as high as I could, and then skied to the bottom. ${ }^{32}$

32 http://www.dailymail.co.uk/travel/article-2589683/Skier-breaks-world-record-skiing-17-countries-21 -days.html, accessed October 1, 2017. 
b. A funeral is scheduled for Sunday for a southwest Missouri man who was badly burned after he rolled into a campfire while he slept. ${ }^{33}$

c. Vincent Jackson caught a 5-yard pass from Glennon as he slid to the side of the end zone to plunge the dagger deep into the heart of Steelers Nation. ${ }^{34}$

Other kinds of result XPs are generally unacceptable, though there is some lexical variation. In some cases, as with intransitive slide, it is hard to get any other result XPs at all. ${ }^{35}$

(59) a. *I slid for so long that day that I slid to exhaustion/to sleep.

b. *John slid unconscious/to unconsciousness when he hit his head on a rock.

(on literal reading)

c. *The glacier was so steep that John slid sick/silly.

d. *Figuring that if he slid fast enough the wind would dry him, John lay down and slid dry, while his friends used towels.

The same is largely true for intransitive ski and roll, though we do note that with sufficient context $60 \mathrm{~d}$ and $61 \mathrm{~d}$ (and possibly $61 \mathrm{~b}$ ) are not quite as unacceptable as the rest.

(60) a. *I skied for so long that day that I skied to exhaustion/to sleep.

b. *Due to lack of oxygen on a high slope, John skied unconscious/to unconsciousness.

c. *The slope was so winding and dizzying that John skied sick/silly.

d. ?Figuring that the wind would dry him off if he moved fast enough, John jumped on his skis and skied dry, while his friends used towels.

(61) a. *I rolled for so long that day that I rolled to exhaustion/to sleep.

b. *John rolled unconscious/to unconsciousness when he hit his head on a rock.

c. *The hillside was so steep that John rolled sick/silly.

d. ?Figuring that the ground would dry him off if he moved fast enough, John lay down and rolled dry, while his friends used towels.

Nonetheless, the acceptability of goal PPs and the overall oddity of nongoal result XPs is consistent with verbs like intransitive ski and roll being scalar change verbs.

With transitive manner-of-motion verbs the situation is more complicated. First, all three verbs under consideration easily allow goal PPs, as predicted if they entail change of location.

(62) a. Stationed just outside the crease in front of the Kings net, Zuccarello slid the puck to the net. ${ }^{36}$

b. Workers rolled the barrels to the shore, and loaded them onto small craft for transport to larger, oceangoing vessels. ${ }^{37}$

c. Soon after, the crowd dragged the two mutilated bodies to Al-Manara Square in the city center and began an impromptu victory celebration. ${ }^{38}$

33 http://www.azcentral.com/news/articles/20111206man-who-rolled-into-campfire-dies.html, accessed October 1, 2017.

$34 \mathrm{https} / /$ www.behindthesteelcurtain.com/pittsburgh-steelers-opinions-reactions-news-updates/2014/9/29 /6862423/steelers-defense-nfl-week-4, accessed October 1, 2017.

${ }^{35}$ Google searches for the result XPs marked as unacceptable here and below turn up few, if any, plausible results, whereas goal PPs are readily found.

$36 \mathrm{https} / /$ www.cbssports.com/nhl/news/gif-mats-zuccarello-misses-sure-goal-from-doorstep-of-net/, accessed October 1, 2017.

${ }^{37} \mathrm{http}: / /$ americanhistory.si.edu/onthewater/exhibition/1_3.html, accessed October 10, 2017.

${ }^{38}$ https://en.wikipedia.org/wiki/2000_Ramallah_lynching, accessed October 5, 2017. 
However, when it comes to result XPs that are not goal PPs, the results are more variable, and here verb choice matters more. Slide seems to us unacceptable with any result $\mathrm{XP}$ other than a goal PP.

(63) a. *Pushing it around as hard as I could, I slid the puck shiny/smooth.

b. *Knowing that the rink was covered in red paint, I slid the puck red.

c. *Figuring that if he slid the puck fast enough the friction would take off all the water, John slid the puck dry.

Conversely, transitive roll and drag are acceptable with at least some nongoal result XPs (see also Rappaport Hovav 2014:276, ex. 38 for similar examples with roll).

(64) a. They rolled the dough flat, then passed it to the next men, who flattened it a little more. ${ }^{39}$

b. Once Hashimoto-san has rolled the dough into a smooth ball, I think we're finished-but we're only just beginning. ${ }^{40}$

(65) a. The horses dragged the logs smooth.

(Washio 1997:6, ex. 17a)

b. Knowing that dragging would strip off the bark, John dragged the logs bare.

These data suggest that some transitive manner-of-motion verbs pattern like manner rather than scalar change verbs, thus showing mixed behavior. However, we suggest that this behavior is still consistent with being scalar change verbs, reflecting instead the presence of further confounding factors that hinge on the specific case of mannerof-motion verbs that also entail scalar change.

First, the fact that nongoal result XPs occur with motion verbs at all is not entirely unexpected. The intuition underlying the result XP test is that there must be compatibility between the scalar changes entailed by the verb and the result XP. The simplest implementation of the diagnostic would be as a compatibility condition on the scalar dimensions determined by the $\mathrm{V}$ and $\mathrm{XP}$, respectively, where if the verb describes change along dimension $\delta$ (e.g. temperature, position, cleanliness), then the result XP must describe a state also on $\delta$. Indeed, this type of dimensional compatibility has been proposed before (albeit not explicitly in terms of scales) as the UNIQUE PATH CONSTRAINT (UPC) of Goldberg 1991:368, 1995:82, which holds that one verbal predicate cannot entail two types of change at once along different real or metaphorical 'paths' (interpreted here as scales; see also the single delimiting constraint of Tenny 1994:79, ex. 155, the further specification constraint of Tortora 1998:341, and the single development constraint of Matsumoto 2006:6, ex. 21, inter alia). This is supported by the fact that V+ result XP combinations or combinations of two result XPs are possible if they describe change along one single dimension, for example, if one further specifies the other.

(66) a. She broke the bottle into ten pieces.

b. The liquid froze solid into a crusty mass.

(Goldberg 1991:371, ex. 19b)

(67) a. *She carried John giddy.

(Simpson 1983:147, ex. 31)

b. *I kicked him out of the room black and blue.

(Matsumoto 2006:2, ex. 5c)

Thus the UPC may underlie the result XP diagnostic (regardless of WHY the UPC should hold, something we do not address here).

It is not surprising, however, that the result XP test does not yield clean results, since the UPC is itself known not to hold categorically (see Levin \& Rappaport Hovav 1995:

39 https://www.pri.org/stories/2014-04-14/secret-matzah-factory-jerusalem-churns-out-passover-matzahs -old-fashioned-way, accessed October 1, 2017.

${ }^{40} \mathrm{http}$ //www.stuff.co.nz/travel/destinations/asia/9628457/Tokyo-tempts-your-tastebuds, accessed October $1,2017$. 
60-61, Matsumoto 2006, Yasuhara 2013, inter alia). For example, Matsumoto (2006) cites numerous examples (from COBUILD) of simultaneous change of location and change of state of one participant.

(68) a. [T] he tide turned and swept the car back into shore to safety.

b. Their mother jumped to safety from a bedroom window.

(Matsumoto 2006:4-5, ex. 15e, 16a)

Matsumoto (2006:6, ex. 21) reenvisions the UPC as the SINGLE DEVELOPMENT CONSTRAINT: two scalar dimensions are compatible if they 'refer to aspects of a single line of development that the [theme] follows'. He gives the contrast in 69, where in 69a it is hard to see how the change entailed by the second result XP is a further development of the first, but it is easy to see in $69 \mathrm{~b}$.

(69) a. *Joe kicked a suitcase open to Bob.

b. Joe flung the door open right into Bob's face. (Matsumoto 2006:7, ex. 22)

Although Matsumoto does not precisely define 'a single line of development', the intuition seems clear that it has to do with the naturalness or necessity that the one change leads to the other. These examples are all very different from those in 67 , where the changes entailed by the various scalar terms do not have any connection owing to naturalness or necessity. In sum, assuming this version of the UPC, the prediction is that verbs and result XPs describing changes along different dimensions will generally be incompatible, but some exceptional cases will be possible.

Given this, there may be a principled reason why such exceptions show up with ski, drag, and roll in 63-65 in particular. Interestingly, all violations of the UPC cited in prior work categorically involve motion as one of the two scalar changes (see the numerous examples in Goldberg 1991:372-76, 1995:81-88, Levin \& Rappaport Hovav 1995:60-61, Matsumoto 2006, and Yasuhara 2013). Why would motion be especially flexible in this regard? This may be because many actions that lead to changes of state involve some type of motion themselves. For example, Dowty (1991:572) lists motion as a property not only of prototypical patients but also of prototypical agents (differing only in that motion for agents is not usually under the control of some other participant, while motion of a patient typically is). Thus the scalar compatibility permitting changes along separate dimensions is independently expected to arise with motion predicates; that is, scalar dimension matters in the behavior of this particular result diagnostic.

But this does not fully explain 63-65, wherein some verbs have inferences that make possible the use of nongoal XPs ( $\mathrm{rag}$, roll) while others do not (slide). If scalar compatibility were solely conditioned by scalar dimension, then since the dimension is the same for all three verbs (i.e. path), their behavior under this diagnostic should be identical. Here we argue a third factor is relevant. Crucially, these verbs all also entail manner, and certain manners may be such that outcomes other than just change of location are likely to arise. Drag and roll in particular have manners involving contact/impact between the theme and a surface, which may naturally yield additional possible outcomes, such as logs becoming bare or smooth by dragging or something becoming clean by rolling, or flat if there is also downward pressure from the causer. Conversely, slide involves relatively frictionless contact and thus may be compatible with fewer additional possible results (though some may be possible in highly particular contexts). For the intransitive manner-of-motion verbs above, which never allow anything other than a goal PP, a similar explanation may obtain. Ski is similar to slide in describing frictionless motion, and climb's manner is just defiance of gravity, perhaps least likely of all to give rise to anything but change of location. Of course, as a referee points out, 
context and world knowledge will matter here. For example, even relatively frictionless motion has some tiny amount of friction that might add up over time, so that ?Over years and years of hard daily use, John slowly slid his puck smooth might be relatively more acceptable than 63a (and to our judgments it is). What kinds of contexts and knowledge matter we do not explore here.

The observations above show that the result XP diagnostic must be interpreted carefully. As originally proposed, the diagnostic was largely designed to handle only canonical cases where result and manner are in complementary distribution, and as such may have produced a skewed view of what factors govern it by presupposing a binary contrast between verbs. In our study of manner + result verbs (Beavers \& Koontz-Garboden 2012:343), we already suggest that many result diagnostics should be rethought to allow for at least a three-way distinction of verbs (pure manner, pure result, and manner + result verbs). Here we have suggested that further relevant variables among result verbs are distinctions in argument structure, the specific scale that forms part of the meaning of the verb, and the additional presence and type of manner also in the verb's meaning. Thus the picture of verb classes we have identified is far more complex than a two- or even three-way typology, and diagnostics such as the result XP test consequently show more nuanced results than anticipated even in Beavers \& Koontz-Garboden 2012. (See also Beavers 2011b:344-45, 361 for further discussion of how scalar change verbs vary in constraints they impose on result XPs.)

5. CONSEQUENCES FOR MANNER/RESUlt COMPLEMENTARITY. A final consequence of our claims is that it raises questions about manner/result complementarity, the hypothesis that a given monomorphemic verb will lexically entail either a manner or a result but not both (Goldberg 2010, Rappaport Hovav \& Levin 2010, Husband 2011, Beavers \& Koontz-Garboden 2012, Mateu \& Acedo-Matellán 2012, Levin \& Rappaport Hovav 2013, Rissman 2016). In particular, with a bifurcation of the notion of result, should the complementarity claim be interpreted more narrowly as a complementarity of manner and scalar result, or more broadly as a complementarity of manner and scalar change? In its strongest form, as complementarity of manner and scalar result, Beavers \& Koontz-Garboden 2012 has already shown that this does not hold, focusing on classes of manner-of-killing verbs, ditransitive ballistic verbs, and cooking verbs. Furthermore, given that all scalar result verbs are also scalar change verbs, defining result more weakly as scalar change does not save complementarity, since the same verbs also counterexemplify the claim in its weaker sense. But so do verbs entailing both manner and scalar change that is not scalar result, such as those discussed above, meaning the counterexamples are far more numerous than previously thought. Finally, were the claim in 37 to be defined as a complementarity of manner and scalar change excluding scalar result (an admittedly rather unintuitive definition of result to use for a claim called 'manner/result complementarity'), then climb and other scalar change verbs that do not entail scalar result still counterexemplify it. In sum, on no understanding of result does manner/result complementarity hold as a truth-conditional claim about surface verbs, further strengthening the argument of Beavers \& Koontz-Garboden 2012 while expanding its empirical base.

That said, an alternative perspective on manner/result complementarity is discussed in both Beavers \& Koontz-Garboden 2012:353-64 and Mateu \& Acedo-Matellán 2012, namely, whether there is manner/result complementarity in terms of how the underlying event structures of verbs are built. For example, can a given event structure have a root in the position of a canonical result root and one in the position of a canonical manner 
root, or must it have just one root in one position even if that root has as part of its truthconditional content lexical entailments describing both manner and result simultaneously? Although using different diagnostics and making different assumptions about event structures, both papers argue that manner/result complementarity in this sense does hold, and Mateu and Acedo-Matellán (2012:217-23) specifically address this claim for climb on the basis of purely syntactic diagnostics (tied to the particular syntactic eventstructural framework they assume), arguing that there are three event structures associated with surface $\operatorname{climb}$, each with one and only one root (although they do not provide a semantics for their analysis, so it is not clear how these event structures derive the interpretations of different uses of $\operatorname{climb}$ ). Since it is not the goal of this article to formalize an event-structural analysis of climb, we leave it to future work to explore this version of manner/result complementarity in light of the semantics of result outlined here or in terms of the diagnostics for structural manner/result complementarity discussed in Beavers \& Koontz-Garboden 2012. The key point is simply that as a truth-conditional claim about verb meanings, manner/result complementarity is counterexemplified by climb, regardless of how one defines result for the purposes of the hypothesis.

6. ConClusion. Taking as a point of departure the by-now widespread definition of result as scalar change, we first documented different senses of climb, demonstrating that all of them have the collection of entailments typical of scalar change save for one, namely, that the theme have a new state on the scale at the end of the event distinct from its initial state. We argued that the prior diagnostics were all picking out different notions, and that the notion of result verb must be divided into those entailing scalar change without scalar result (e.g. climb) and those entailing scalar result, that is, scalar change with a distinct result (e.g. break and cool). We further demonstrated that different senses of climb are subdivided by the quantized vs. nonquantized distinction that characterizes standard scalar result verbs (e.g. break vs. cool), further supporting the conclusion that there is scalar change in its meaning (since the quantized/nonquantized distinction presupposes scalar change), and ultimately deriving a broad four-way typology of result verbs.

The observation that scalar change verbs need not entail a new result has several significant consequences. First, it turns out that various previously discussed result and quantized/nonquantized diagnostics were picking out either larger or smaller classes of verbs than previously assumed. Second, the existence of scalar change without scalar result raises the possibility that scalar change verbs may exist in unexpected domains. We demonstrated that climb also entails manner in all of its uses and is thus a manner-ofmotion verb, and furthermore at least some other manner-of-motion verbs are similar in also entailing scalar change, arguing against the clean divide between path and manner verbs from work rooted in the Talmy typology. Third, the presence of mannerful scalar change verbs in turn helps explain various subtleties of the result XP test for scalar change, which demonstrates that manner-of-motion verbs entailing scalar change may be a linguistically significant class. Finally, these data support and provide further empirical basis to the argument against manner/result complementarity in Beavers \& KoontzGarboden 2012. Ultimately, we have shown that there are different ways of being a result verb, and that the distinctions in this domain crosscut not only expected distinctions based on previous understanding of result verbs (i.e. the quantized/nonquantized change distinction), but the manner/nonmanner distinction as well. A final question is what consequences this work will have for the nature of event structures themselves, something we leave for now to future work. 


\section{REFERENCES}

Asher, Nicholas, and Pierre Sablayrolles. 1996. A typology and discourse semantics for motion verbs and spatial PPs in French. Lexical semantics: A problem of polysemy, ed. by James Pustejovsky and Branimir Boguraev, 163-209. Oxford: Clarendon.

BAKER, MARK C. 1997. Thematic roles and syntactic structure. Elements of grammar, ed. by Liliane Haegeman, 73-137. Dordrecht: Kluwer.

Bassa Vanrell, Maria del Mar. 2013. Preposition typology with manner of motion verbs in Spanish. Austin: The University of Texas at Austin master's thesis.

BEAVERS, JOHN. 2008. Scalar complexity and the structure of events. Event structures in linguistic form and interpretation, ed. by Johannes Dölling, Tatjana Heyde-Zybatow, and Martin Schäfer, 245-65. Berlin: Mouton de Gruyter.

BEAVERS, JoHn. 2010. The structure of lexical meaning: Why semantics really matters. Language 86.821-64. DOI: 10.1353/lan.2010.0040.

BEAVERS, JoHN. 2011a. An aspectual analysis of ditransitive verbs of caused possession in English. Journal of Semantics 28.1-54. DOI: 10.1093/jos/ffq014.

Beavers, John. 2011b. On affectedness. Natural Language and Linguistic Theory 29.33570. DOI: $10.1007 / \mathrm{s} 11049-011-9124-6$.

BEAVERS, JoHn. 2012a. Lexical aspect and multiple incremental themes. Telicity, change, and state: A cross-categorial view of event structure, ed. by Violeta Demonte and Louise McNally, 23-59. Oxford: Oxford University Press.

Beavers, John. 2012b. Resultative constructions. The Oxford handbook on tense and aspect, ed. by Robert I. Binnick, 908-33. Oxford: Oxford University Press.

BEAVERS, JoHn. 2013. Aspectual classes and scales of change. Linguistics 54.681-706. DOI: 10.1515/ling-2013-0024.

Beavers, John, and Andrew Koontz-Garboden. 2012. Manner and result in the roots of verbal meaning. Linguistic Inquiry 43.331-69. DOI: 10.1162/LING_a_00093.

Beavers, John; Beth Levin; and Shiao Wei Tham. 2010. The typology of motion expressions revisited. Journal of Linguistics 46.331-77. DOI: 10.1017/S0022226709990272.

Croft, William, and D. Alan Cruse. 2004. Cognitive linguistics. Cambridge: Cambridge University Press.

Cummins, Sarah. 1996. Movement and direction in French and English. Toronto Working Papers in Linguistics 15.31-54. Online: http://twpl.library.utoronto.ca/index.php/twpl /article/view/6306.

Davis, Anthony. 2001. Linking by types in the hierarchical lexicon. Stanford, CA: CSLI Publications.

Davis, Anthony, and Jean-Pierre Koenig. 2000. Linking as constraints on word classes in a hierarchical lexicon. Language 76.56-91. DOI: 10.1353/lan.2000.0068.

De Swart, HenriëtTe. 1998. Aspect shift and coercion. Natural Language and Linguistic Theory 16.347-85. DOI: 10.1023/A:1005916004600.

Doron, Edit; Malka Rappaport Hovav; and Ivy Sichel (eds.) 2010. Syntax, lexical semantics, and event structure. Oxford: Oxford University Press.

DowTY, DAvID. 1979. Word meaning and Montague grammar. Dordrecht: Reidel.

DowTy, DAVID. 1991. Thematic proto-roles and argument selection. Language 67.547-619. DOI: $10.2307 / 415037$.

FÁbregas, Antonio. 2007. The exhaustive lexicalisation principle. Nordlyd: Tromsø Working Papers in Linguistics 34(2).165-99. DOI: 10.7557/12.110.

Fillmore, Charles. 1970. The grammar of hitting and breaking. Readings in English transformational grammar, ed. by Roderick Jacobs and Peter Rosenbaum, 120-33. Waltham, MA: Ginn.

Fillmore, Charles. 1982. Towards a descriptive framework for spatial deixis. Speech, place, and action, ed. by Robert J. Jarvella and Wolfgang Klein, 31-59. New York: John Wiley \& Sons.

Folli, Raffaella, and Heidi Harley. 2004. Consuming results: Flavors of little- $v$. Aspectual enquiries, ed. by Paula Kempchinsky and Roumyana Slabakova, 1-25. Dordrecht: Kluwer.

Folli, RafFaella, and Heidi Harley. 2006. On the licensing of causatives of directed motion: Waltzing Matilda all over. Studia Linguistica 60.121-55. DOI: 10.1111/j.1467 $-9582.2006 .00135 . \mathrm{x}$. 
Folli, RAFFAELla, and Gillian RAmCHAND. 2002. Event structure composition: The case of goal of motion and resultative constructions in Italian and Scottish Gaelic. Proceedings of Perspectives on Aspect Conference, ed. by Henk J. Verkuyl. Utrecht: OTS.

Folli, RafFaella, and Gillian Ramchand. 2005. Prepositions and results in Italian and English: An analysis from event decomposition. Perspectives on aspect, ed. by Henk Verkuyl, Henriëtte de Swart, and Angeliek van Hout, 81-105. Dordrecht: Kluwer. DOI: 10.1007/1-4020-3232-3 5.

Geuder, Wilhelm. 2009. Descendre en grimpant: Une étude contrastive de l'interaction entre déplacement et manière de mouvement. Langages 175.123-39.

Geuder, Wilhelm, and Matthias Weisgerber. 2008. Manner of movement and the conceptualisation of force. Slides of talk given at Journée d'étude 'Il y a manière et manière', Université d'Artois, Arras, March 28, 2008.

Goldberg, Adele E. 1991. It can't go down the chimney up: Paths and the English resultative. Berkeley Linguistics Society 17.368-78. DOI: 10.3765/bls.v17i0.1614.

GoldBerg, AdELE E. 1995. Constructions: A construction grammar approach to argument structure. Chicago: University of Chicago Press.

Goldberg, Adele E. 2010. Verbs, constructions, and semantic frames. In Doron et al., 39-58. DOI: 10.1093/acprof:oso/9780199544325.003.0003.

Grimshaw, JANE. 2005. Words and structure. Stanford, CA: CSLI Publications.

Hale, Kenneth L., and Samuel Jay Keyser. 1993. On argument structure and the lexical expression of syntactic relations. The view from building 20: Essays in linguistics in honor of Sylvain Bromberger, ed. by Kenneth Hale and Samuel Jay Keyser, 53-109. Cambridge, MA: MIT Press.

Hale, Kenneth L., and Samuel Jay Keyser. 1997. The limits of argument structure. Theoretical issues at the morphology-syntax interface, ed. by Amaya Mendikoetxea and Myriam Uribe-Etxebarria, 203-30. Bilbao: Universidad del Pais Vasco, Ueskal Herriko Universitatea.

Hale, Kenneth L., and Samuel Jay Keyser. 2002. Prolegomenon to a theory of argument structure. Cambridge, MA: MIT Press.

Harley, Heidi. 2003. Possession and the double object construction. Linguistic variation yearbook 2, ed. by Pierre Pica and Johan Rooryck, 31-70. Amsterdam: John Benjamins.

Hay, Jennifer; Christopher Kennedy; and Beth Levin. 1999. Scalar structure underlies telicity in 'degree achievements'. Proceedings of Semantics and Linguistic Theory (SALT) 9.127-44. DOI: 10.3765/salt.v9i0.2833.

Husband, E. Matthew. 2011. Rescuing manner/result complementarity from certain death. Chicago Linguistic Society 47(1).111-24. Online: http://www.ingentaconnect .com/contentone/cls/pcls/2011/00000047/00000001/art00008.

INAGAKI, SHUNJI. 2002. Motion verbs with locational/directional PPs in English and Japanese. Canadian Journal of Linguistics/Revue canadienne de linguistique 47.187-234. DOI: $10.1017 /$ S0008413100022945.

JACKENDOFF, RAY. 1985. Multiple subcategorization and the $\theta$-criterion: The case of climb. Natural Language and Linguistic Theory 3.271-95. DOI: 10.1007/BF00154264.

JACKENDOFF, RAY. 1990. Semantic structures. Cambridge, MA: MIT Press.

Jones, Michael A. 1996. Foundations of French syntax. Cambridge: Cambridge University Press.

Kearns, Kate. 2000. Semantics. New York: St. Martin's.

Kennedy, Christopher. 2001. Polar opposition and the ontology of 'degrees'. Linguistics and Philosophy 24.33-70. DOI: 10.1023/A:1005668525906.

Kennedy, Christopher, and Beth Levin. 2008. Measure of change: The adjectival core of degree achievements. Adjectives and adverbs: Syntax, semantics, and discourse, ed. by Louise McNally and Christopher Kennedy, 156-82. Oxford: Oxford University Press.

Kiparsky, PaUl. 1997. Remarks on denominal verbs. Argument structure, ed. by Alex Alsina, Joan Bresnan, and Peter Sells, 473-99. Stanford, CA: CSLI Publications.

Koenig, Jean-Pierre; Douglas Roland; Hongoak Yun; and Gail Mauner. 2015. Which event properties matter for which cognitive task? Cognitive science perspectives on verb representation and processing, ed. by Roberto G. de Almeida and Christina Manouilidou, 213-34. Dordrecht: Springer.

Koontz-Garboden, Andrew. 2010. The lexical semantics of derived statives. Linguistics and Philosophy 33.285-324. DOI: 10.1007/s10988-011-9082-9. 
Kratzer, Angelika. 2004. Telicity and the meaning of objective case. The syntax of time, ed. by Jacqueline Guéron and Jacqueline Lecarme, 389-423. Cambridge, MA: MIT Press.

KrifKa, MANFRED. 1998. The origins of telicity. Events and grammar, ed. by Susan Rothstein, 197-235. Dordrecht: Kluwer.

LAKOFF, GeORGE. 1965. On the nature of syntactic irregularity. Bloomington: Indiana University dissertation. [Published as Irregularity in syntax, New York: Holt, Rinehart, and Winston, 1970.]

LAKOFF, GEORgE. 1990. The invariance hypothesis: Is abstract reason based on imageschemas? Cognitive Linguistics 1.39-74. DOI: 10.1515/cogl.1990.1.1.39.

Levin, Beth. 1993. English verb classes and alternations: A preliminary investigation. Chicago: University of Chicago Press.

LEVIN, BETH. 2015. Verb classes within and across languages. Valency classes in the world's languages, vol. 2: Case studies from Austronesia, the Pacific, the Americas, and theoretical outlook (Comparative handbooks of linguistics 2), ed. by Bernard Comrie and Andrej Malchukov, 1627-70. Berlin: De Gruyter.

Levin, Beth, and Malka RapPaport Hovav. 1995. Unaccusativity: At the syntax-lexical semantics interface. Cambridge, MA: MIT Press.

Levin, Beth, and Malka RapPaPORT Hovav. 2008. Lexicalized manner and result are in complementary distribution. Handout of talk given at the 24th meeting of the Israeli Association for Theoretical Linguistics, 26-27 October 2008.

Levin, Beth, and Malka Rappaport Hovav. 2013. Lexicalized meaning and manner/ result complementarity. Studies in the composition and decomposition of event predicates, ed. by Boban Arsenijević, Berit Gehrke, and Rafael Marín, 49-70. Dordrecht: Springer. DOI: 10.1007/978-94-007-5983-1 3.

Lupsa, Cornelia Daniela. 2003. Second delimiters as subject oriented resultative phrases. Explorations in English Linguistics 18.1-11.

Marantz, Alec. 1997. No escape from syntax: Don't try morphological analysis in the privacy of your own lexicon. University of Pennsylvania Working Papers in Linguistics (Proceedings of the 21st annual Penn Linguistics Colloquium) 4(2).201-25. Online: http://repository.upenn.edu/pwpl/vol4/iss2/14.

Mateu, Jaume, and Víctor Acedo-Matellán. 2012. The manner/result complementarity revisited: A syntactic approach. Syntax and semantics, vol. 28: The end of argument structure, ed. by María Cristina Cuervo and Yves Roberge, 209-28. London: Emerald.

Mateu, Jaume, and Gemma Rigau. 2002. A minimalist account of conflation processes: Parametric variation at the lexicon-syntax interface. Theoretical approaches to universals, ed. by Artemis Alexiadou, 211-36. Amsterdam: John Benjamins.

Matsumoto, Yo. 2006. Constraints on the co-occurrence of spatial and non-spatial paths in English: A closer look at the unique path constraint. Paper presented at the Fourth International Conference on Construction Grammar, University of Tokyo. Online: http:// www.lit.kobe-u.ac.jp/ yomatsum/papers/unique\%20path.pdf.

McCAwley, James D. 1971. Prelexical syntax. Report of the 22nd Annual Roundtable Meeting on Linguistics and Language Studies, 19-33. Washington, DC: Georgetown University Press.

Nam, SEungho. 2000. A typology of locatives and event composition in English. Language Research 36.689-714.

Pesetsky, David. 1995. Zero syntax: Experiencer and cascades. Cambridge, MA: MIT Press.

Pinker, Steven. 1989. Learnability and cognition: The acquisition of argument structure. Cambridge, MA: MIT Press.

Piñón, Christopher. 1993. Paths and their names. Chicago Linguistic Society (Parasession on conceptual, semantic \& grammatical representation) 29(2).287-303.

Ramchand, Gillian. 2008. Verb meaning and the lexicon: A first phase syntax. Cambridge: Cambridge University Press.

RAPPAPORT Hovav, Malka. 2008. Lexicalized meaning and the internal structure of events. In Rothstein 2008, 13-42.

RAPPAPORT Hovav, Malka. 2014. Building scalar changes. The syntax of roots and the roots of syntax, ed. by Artemis Alexiadou, Hagit Borer, and Florian Schäfer, 259-81. Oxford: Oxford University Press. 
Rappaport Hovav, Malka, and Beth Levin. 1998. Building verb meanings. The projection of arguments: Lexical and compositional factors, ed. by Miriam Butt and Wilhelm Geuder, 97-133. Stanford, CA: CSLI Publications.

RAPPAPORT Hovav, Malka, and Beth Levin. 2001. An event structure account of English resultatives. Language 77.766-97. DOI: 10.1353/lan.2001.0221.

Rappaport Hovav, MaLKa, and Beth Levin. 2010. Reflections on manner/result complementarity. In Doron et al., 21-38. DOI: 10.1093/acprof:oso/9780199544325.003.0002.

Rissman, LiLIA. 2016. Cinderella broke and broke: Object deletion and manner-result complementarity. Chicago Linguistic Society 51(1).425-39.

Ross, John Robert. 1972. Act. Semantics of natural language, ed. by Donald Davidson and Gilbert Harman, 70-126. Dordrecht: Reidel.

Rothstein, Susan. 2004. Structuring events. Oxford: Blackwell.

Rothstein, SusAn (ed.) 2008. Lexicalized meaning and the internal structure of events. Amsterdam: John Benjamins.

SchWARZSCHILD, Roger, and Karina Wilkinson. 2002. Quantifiers in comparatives: A semantics of degree based on intervals. Natural Language Semantics 10.1-41. DOI: 10.1023/A:1015545424775.

Simpson, Jane. 1983. Resultatives. Papers in lexical-functional grammar, ed. by Lori Levin, Malka Rappaport, and Annie Zaenen, 143-57. Bloomington: Indiana University Linguistics Club.

SLobin, Dan I. 1996. Two ways to travel: Verbs of motion in English and Spanish. Grammatical constructions: Their form and meaning, ed. by Masayoshi Shibatani and Sandra A. Thompson, 195-219. Oxford: Oxford University Press.

Son, Minjeong, and Peter Svenonious. 2008. Microparameters of cross-linguistic variation: Directed motion and resultatives. Western Conference on Linguistics (WECOL) 27.388-96. Online: http://www.lingref.com/cpp/wccfl/27/abstract1854.html.

TALmy, LeONARD. 1975. Syntax and semantics, vol. 4: Semantics and syntax of motion, ed. by John P. Kimball, 181-238. New York: Academic Press.

TALMY, LEONARD. 1985. Lexicalization patterns. Language typology and syntactic description, vol. 3: Grammatical categories and the lexicon, ed. by Timothy Shopen, 57-149. Cambridge: Cambridge University Press.

Talmy, LeONARD. 2000. Towards a cognitive semantics. Cambridge, MA: MIT Press.

Tatevosov, Sergei. 2012. Telicity, measures, and endpoints. Proceedings of Sinn und Bedeutung 16 (MIT Working Papers in Linguistics), 585-98. Online: http://mitwpl.mit .edu/open/sub16/Tatevosov.pdf.

Tenny, CARol. 1994. Aspectual roles and the syntax-semantics interface. Dordrecht: Kluwer.

Tham, Shiao Wei; John Beavers; and Beth Levin. 2012. Directional interpretations with locative prepositions. Talk given at the Meaning of P Workshop, Bochum, Germany.

Tortora, Christina M. 1998. Verbs of inherently directed motion are compatible with resultative phrases. Linguistic Inquiry 29.338-45. DOI: 10.1162/ling.1998.29.2.338.

Van Valin, Robert D., JR., and Randy J. LaPolla. 1997. Syntax: Structure, meaning, and function. Cambridge: Cambridge University Press.

Verspoor, Cornelia Maria. 1997. Contextually-dependent lexical semantics. Edinburgh: University of Edinburgh dissertation.

WASHIO, RYUICHI. 1997. Resultatives, compositionality, and language variation. Journal of East Asian Linguistics 6.1-49. DOI: 10.1023/A:1008257704110.

Wechsler, Stephen. 1997. Resultative predicates and control. Texas Linguistics Forum (The syntax and semantics of predication) 38.307-21.

WeCHSLER, STEPHEN. 2005. Resultatives under the 'event-argument homomorphism' model of telicity. The syntax of aspect, ed. by Nomi Erteschik-Shir and Tova Rapoport, 255-73. Oxford: Oxford University Press.

WIENOLD, GöTZ. 1995. Lexical and conceptual structures in expressions for movement and space: With reference to Japanese, Korean, Thai, and Indonesian as compared to English and German. Lexical knowledge in the organization of language, ed. by Urs Egli, Peter E. Pause, Cristoph Schwarze, Arnim von Stechow, and Götz Wienold, 301-40. Amsterdam: John Benjamins.

Wunderlich, Dieter. 1997. Cause and the structure of verbs. Linguistic Inquiry 28.27-68. Online: http://www.jstor.org/stable/4178964. 
Yasuhara, Masaki. 2013. Further specification analysis of the unique path constraint effect: From the perspective of spatial extension. English Linguistics Research 2.141-54. DOI: 10.5430 /elr.v2n2p141.

Zlatev, Jordan, and Peerapat Yangklang. 2004. A third way to travel: The place of Thai in motion-event typology. Relating events in narrative 2: Typological and contextual perspectives, ed. by Sven Strömqvist and Ludo Verhoeven, 219-57. Mahwah, NJ: Lawrence Erlbaum.

Zubizarreta, Maria Luisa, and EungJeOng OH. 2007. On the syntactic composition of manner and motion. Cambridge, MA: MIT Press.

Zwarts, Joost. 2003. Paths round a prototype. Proceedings of the ACL-SIGSEM Workshop on the Linguistic Dimensions of Prepositions and their Use in Computational Linguistics Formalisms and Applications, ed. by Patrick Saint-Dizier, 228-38. Toulouse: IRIT.

Zwarts, Joost. 2005. Prepositional aspect and the algebra of paths. Linguistics and Philosophy 28.739-79. DOI: 10.1007/s10988-005-2466-y.

Zwarts, Joost. 2006. Event shape: Paths in the semantics of verbs. Paper presented at the Workshop on the Geometric Structure of Events, Konstanz, October 7-8, 2004. Online: http://www.hum.uu.nl/medewerkers/j.zwarts/EventShape.pdf.

ZwarTs, Joost. 2008. Aspects of a typology of direction. In Rothstein 2008, 79-106.

Zwarts, Joost, and YoAD WinTER. 2000. Vector space semantics: A model-theoretic analysis of locative prepositions. Journal of Logic, Language, and Information 9.169-211. DOI: 10.1023/A:1008384416604.

Beavers

Department of Linguistics

The University of Texas at Austin

305 E. 23rd Street, Mail Code B5100

Austin, TX 78712

[jtbeavers@utexas.edu]

Koontz-Garboden

Department of Linguistics and English Language

The University of Manchester

Samuel Alexander Building

Oxford Road M13 9PL

Manchester, UK

[andrewkg@manchester.ac.uk]
[Received 25 June 2015;

revision invited 20 December 2015; revision received 15 August 2016; revision invited 7 December 2016; revision received 8 February 2017; accepted 18 February 2017] 